\title{
SARS-CoV-2 infection and persistence throughout the human body and brain
}

Daniel Chertow ( $\nabla$ chertowd@cc.nih.gov )

National Institutes of Health https://orcid.org/0000-0002-1675-1728

Sydney Stein

National Institutes of Health https://orcid.org/0000-0002-0259-4485

\section{Sabrina Ramelli}

National Institutes of Health

\section{Alison Grazioli}

National Institutes of Health

Joon-Yong Chung

$\mathrm{NCl}$ https://orcid.org/0000-0001-5041-5982

Manmeet Singh

National Institutes of Health

Claude Kwe Yinda

National Institute of Allergy and Infectious Diseases

Clayton Winkler

National Institutes of Health

James Dickey

National Institutes of Health

Kris Ylaya

National Cancer Institute

Sung Hee Ko

National Institutes of Health

Andrew Platt

National Institutes of Health

\section{Peter Burbelo}

8Dental Clinical Research Core, NIDCR, NIH https://orcid.org/0000-0003-1717-048X

\section{Martha Quezado}

National Institutes of Health

\section{Stefania Pittaluga}

$\mathrm{NIH}$

\section{Madeleine Purcell}

University of Maryland School of Medicine

\section{Vincent Munster}


National Institute of Allergy and Infectious Diseases https://orcid.org/0000-0002-2288-3196

\section{Frida Belinky}

$\mathrm{NIH}$

\section{Marcos Ramos-Benitez}

National Institutes of Health

\section{Eli Boritz}

National Institutes of Health

\section{Daniel Herr}

University of Maryland School of Medicine

\section{Joseph Rabin}

University of Maryland School of Medicine

\section{Kapil Saharia}

University of Maryland School of Medicine

\section{Ronson Madathil}

University of Maryland School of Medicine

\section{Ali Tabatabai}

University of Maryland School of Medicine

\section{Shahabuddin Soherwardi}

TidalHealth Peninsula Regional

\section{Michael McCurdy}

University of Maryland St. Joseph Medical Center https://orcid.org/0000-0001-5319-0475

\section{Karin Peterson}

National Institutes of Health

Jeffrey Cohen

National Institutes of Health

\section{Emmie de Wit}

National Institute of Allergy and Infectious Diseases https://orcid.org/0000-0002-9763-7758

\section{Kevin Vannella}

National Institutes of Health

\section{Stephen Hewitt}

National Cancer Institute, National Institutes of Health https://orcid.org/0000-0001-8283-1788

\section{David Kleiner}

National Cancer Institute https://orcid.org/0000-0003-3442-4453

\section{Biological Sciences - Article}

\section{Keywords:}

Posted Date: December 20th, 2021 
DOI: https://doi.org/10.21203/rs.3.rs-1139035/v1

License: (a) (i) This work is licensed under a Creative Commons Attribution 4.0 International License. Read Full License 
Authors:

4 Sydney R. Stein ${ }^{1,2}$, Sabrina C. Ramelli ${ }^{3}$, Alison Grazioli ${ }^{4}$, Joon-Yong Chung $^{5}$, Manmeet Singh ${ }^{6}$,

5 Claude Kwe Yinda ${ }^{6}$, Clayton W. Winkler ${ }^{7}$, James M. Dickey ${ }^{1,2}$, Kris Ylaya ${ }^{5}$, Sung Hee $\mathrm{Ko}^{8}$,

6 Andrew Platt ${ }^{1,2}$, Peter D. Burbelo ${ }^{9}$, Martha Quezado $^{5}$, Stefania Pittaluga ${ }^{5}$, Madeleine Purcell ${ }^{10}$,

7 Vincent J. Munster ${ }^{6}$, Frida Belinky ${ }^{8}$, Marcos J. Ramos-Benitez ${ }^{1,2,11}$, Eli A. Boritz ${ }^{8}$, Daniel L.

8 Herr $^{12}$, Joseph Rabin ${ }^{13}$, Kapil K. Saharia ${ }^{14,15}$, Ronson J. Madathil ${ }^{16}$, Ali Tabatabai ${ }^{17}$,

9 Shahabuddin Soherwardi ${ }^{18}$, Michael T. McCurdy ${ }^{19,17}$, NIH COVID-19 Autopsy Consortium^,

10 Karin E. Peterson ${ }^{7}$, Jeffrey I. Cohen ${ }^{19}$, Emmie de Wit ${ }^{6}$, Kevin M. Vannella ${ }^{1,2}$, Stephen M.

11 Hewitt $^{5}$, David E. Kleiner ${ }^{5}$, Daniel S. Chertow ${ }^{1,2^{*}}$

12 Affiliations:

13 1. Emerging Pathogens Section, Critical Care Medicine Department, Clinical Center, $14 \quad$ National Institutes of Health, Bethesda, MD, USA

2. Laboratory of Immunoregulation, National Institute of Allergy and Infectious Diseases, National Institutes of Health, Bethesda, MD, USA

3. Critical Care Medicine Department, Clinical Center, National Institutes of Health, Bethesda, MD, USA

4. Kidney Disease Section, Kidney Diseases Branch, National Institute of Diabetes and Digestive and Kidney Diseases, National Institutes of Health, Bethesda, MD, USA Institutes of Health, Bethesda, MD, USA 
6. Laboratory of Virology, Division of Intramural Research, National Institute of Allergy and Infectious Diseases, National Institute of Health, Hamilton, MT, USA

7. Laboratory of Persistence Viral Diseases, Rocky Mountain Laboratories, National Institute of Allergy and Infectious Diseases, National Institute of Health, Hamilton, MT, USA

8. Vaccine Research Center, National Institute of Allergy and Infectious Diseases, National Institutes of Health, Bethesda, MD, USA

9. National Institute of Dental and Craniofacial Research, National Institutes of Health, Bethesda, MD, USA

10. University of Maryland School of Medicine, Baltimore, MD, USA

11. Postdoctoral Research Associate Training Program, National Institute of General Medical Sciences, National Institutes of Health, Bethesda, MD, USA

12. R Adams Cowley Shock Trauma Center, Department of Medicine and Program in Trauma, University of Maryland School of Medicine, Baltimore, MD, USA

13. R Adams Cowley Shock Trauma Center, Department of Surgery and Program in Trauma, University of Maryland School of Medicine, Baltimore, MD, USA

14. Department of Medicine, Division of Infectious Disease, University of Maryland School of Medicine, Baltimore, MD, USA

15. Institute of Human Virology, University of Maryland School of Medicine, Baltimore, MD, USA

16. Department of Surgery, Division of Cardiac Surgery, University of Maryland School of Medicine, Baltimore, MD, USA 
17. Department of Medicine, Division of Pulmonary and Critical Care Medicine, University of Maryland School of Medicine, Baltimore, MD, USA

18. Hospitalist Department, TidalHealth Peninsula Regional, Salisbury, MD, USA

19. Division of Critical Care Medicine, Department of Medicine, University of Maryland St. Joseph Medical Center, Towson, MD, USA

20. Medical Virology Section, Laboratory of Infectious Diseases, National Institute of

Allergy and Infectious Diseases, National Institutes of Health, Bethesda MD

60

61

62

63

64

65

66

67 
COVID-19 is known to cause multi-organ dysfunction ${ }^{1-3}$ in acute infection, with prolonged symptoms experienced by some patients, termed Post-Acute Sequelae of SARSCoV-2 (PASC) $)^{4-5}$. However, the burden of infection outside the respiratory tract and time to viral clearance is not well characterized, particularly in the brain ${ }^{3,6-14}$. We performed complete autopsies on 44 patients with COVID-19 to map and quantify SARS-CoV-2 distribution, replication, and cell-type specificity across the human body, including brain, from acute infection through over seven months following symptom onset. We show that

SARS-CoV-2 is widely distributed, even among patients who died with asymptomatic to mild COVID-19, and that virus replication is present in multiple pulmonary and extrapulmonary tissues early in infection. Further, we detected persistent SARS-CoV-2 RNA in multiple anatomic sites, including regions throughout the brain, for up to 230 days following symptom onset. Despite extensive distribution of SARS-CoV-2 in the body, we observed a paucity of inflammation or direct viral cytopathology outside of the lungs. Our data prove that SARS-CoV-2 causes systemic infection and can persist in the body for months.

Main text:

Infection with severe acute respiratory syndrome coronavirus 2 (SARS-CoV-2), the causative agent of coronavirus disease 2019 (COVID-19), has well described pulmonary and extrapulmonary manifestations ${ }^{1-3}$, including multiorgan failure and shock among severe and fatal cases. Some survivors experience Post-Acute Sequelae of SARS-CoV-2 (PASC) - also known as Long COVID — with cardiovascular, pulmonary, and neurological manifestations with or without functional impairment ${ }^{4-5}$. While autopsy studies of fatal COVID-19 cases support the ability of SARS-CoV-2 to infect multiple organs ${ }^{3,7-12}$, extra-pulmonary organs often lack histopathological 
91 evidence of direct virally-mediated injury or inflammation ${ }^{10-14}$. The paradox of extra-pulmonary

92 infection without injury or inflammation raises many pathogen- and host-related questions.

93 These questions include, but are not limited to: What is the burden of infection within versus

94 outside of the respiratory tract? What cell types are infected across extra-pulmonary tissues, and

95 do they support SARS-CoV-2 infection and replication? In the absence of cellular injury and

96 inflammation in extra-pulmonary tissues, does SARS-CoV-2 persist, and if so, over what

97 interval? Does SARS-CoV-2 evolve as it spreads to and persists in different anatomical

98 compartments?

To inform these pathogen-focused questions and to evaluate for the presence or absence of associated histopathology in matched tissue specimens, we performed extensive autopsies on

101 a diverse population of 44 individuals who died from or with COVID-19 up to 230 days

102 following initial symptom onset. Our approach focused on timely, systematic, and

103 comprehensive tissue sampling and preservation of adjacent tissue samples for complementary

104 analyses. We performed droplet digital polymerase chain reaction (ddPCR) for sensitive

105 detection and quantification of SARS-CoV-2 gene targets in all tissue samples collected. To

106 elucidate SARS-CoV-2 cell-type specificity and validate ddPCR findings, we performed in situ

107 hybridization (ISH) broadly across sampled tissues. Immunohistochemistry (IHC) was used to

108 further validate cell-type specificity in the brain where controversy remains on the regional

109 distribution and cellular tropism of SARS-CoV-2 infection. In all samples where SARS-CoV-2

110 RNA was detected by ddPCR, we performed qRT-PCR to detect subgenomic (sg)RNA, an assay

111 suggestive of recent virus replication ${ }^{15}$. We confirmed the presence of replication-competent

112 SARS-CoV-2 in extrapulmonary tissues by virus isolation in cell culture. Lastly, in six 
113 individuals, we measured the diversity and anatomic distribution of intra-individual SARS-CoV-

1142 variants using high-throughput, single-genome amplification and sequencing (HT-SGS).

115 We categorized autopsy cases of SARS-CoV-2 infection as "early" (n=17), "mid"

$116(n=13)$, or "late" $(n=14)$ by illness day (D) at the time of death, being $\leq$ D14, D15-D30, or $\geq$ D31,

117 respectively. We defined persistence as presence of SARS-CoV-2 RNA among late cases. Due to

118 the extensive tissue collection, we analyzed and described the results in terms of grouped tissue

119 categories as the following: respiratory tract; cardiovascular; lymphoid; gastrointestinal; renal

120 and endocrine; reproductive; muscle, skin, adipose, \& peripheral nerves; and brain.

121

122 Autopsy cohort overview

123 Between April 26, 2020 and March 2, 2021, we performed autopsies on 44 PCR-

124 confirmed cases (Extended Data Fig. 1). SARS-CoV-2 seroconversion was detected in 38 of

125 these cases (Supplementary Data 1); three early cases (P27, P36, P37) had not seroconverted and 126 perimortem plasma was unavailable for the other three cases (P3, P4, P15). Extensive sampling

127 of the brain was accomplished in 11 of the 44 cases (Fig. 1). The cohort was $29.5 \%$ female with

128 a mean age of 59.2 years and was diverse across race and ethnicity (Extended Data Table 1).

$12995.5 \%$ of patients had at least one comorbidity, with hypertension $(54.5 \%)$, obesity $(52.3 \%)$, and

130 chronic respiratory disease $(34.1 \%)$ being most common. Patients presented to the hospital a

131 mean of 9.4 days following symptom onset and were hospitalized a mean of 26.4 days. Overall,

132 the mean interval from symptom onset to death was 35.2 days and the mean postmortem interval

133 was 26.2 hours. $81.8 \%$ of patients required intubation with invasive mechanical ventilation,

$13422.7 \%$ received extracorporeal membrane oxygenation (ECMO) support, and 40.9\% required

135 renal replacement therapy. Vasopressors, systemic steroids, systemic anticoagulation, and 
antibiotics were commonly administered (Extended Data Table 1). Individual patient-level demographic and clinical information can be found in Extended Data Table 2.

\section{Widespread infection and persistence}

SARS-CoV-2 RNA was detected in all 44 cases and across 79 of 85 anatomical locations and body fluids sampled (Extended Data Fig. 2, Supplementary Data 1). The highest burden of SARS-CoV-2 RNA (i.e., > 100,000 N gene copies/ng RNA input) was detected in the respiratory tract of early cases (Figure 1), but we detected at least $100 \mathrm{~N}$ gene copies/ng RNA input from every tissue group besides reproductive tissues from multiple individuals among early cases. The mean SARS-CoV-2 $\mathrm{N}$ gene copies/ng RNA detected from tissues in each grouping among early cases are as follows: 9,210.10 across respiratory tissues; 38.75 across cardiovascular tissues; 30.01 across lymphoid tissues; 24.68 across gastrointestinal tissues; 12.76 across renal and endocrine tissues; 0.36 across reproductive tissues; 27.50 across muscle, peripheral nerve, adipose, and skin tissues; 57.40 across ocular tissues; and 32.93 across brain tissues (Extended Data Table 3).

With a few exceptions, the overall burden of SARS-CoV-2 RNA decreased by a log or more across tissue categories among mid cases, and further decreased among late cases.

However, several mid and late cases had high levels ( $\geq 5 \mathrm{~N}$ gene copies/ng RNA input) detected among multiple tissues (Extended Data Fig. 2). Further, persistence of low-level SARS-CoV-2 RNA (0.0004 to $<0.5 \mathrm{~N}$ gene copies/ng RNA input) was frequently detected across multiple tissue categories among all late cases, despite being undetectable in plasma (Extended Data Fig. 2, Supplementary Data 1). Notably, SARS-CoV-2 RNA was detected in the brains of all six late 
cases and across most locations evaluated in the brain in five of these six, including P42 who died at D230 (Fig. 1).

Overall, SARS-CoV-2 RNA was detected in respiratory tissue of 43/44 cases (97.7\%); cardiovascular tissue of 35/44 cases (79.5\%); lymphoid tissue of 38/44 cases $(86.4 \%)$; gastrointestinal tissue of 32/44 (72.7\%); renal and endocrine tissue of 28/44 cases (63.6\%); reproductive tissue in 17/40 cases (42.5\%); muscle, skin, adipose, and peripheral nervous tissue in $30 / 44$ cases $(68.2 \%)$; ocular tissue and humors of 22/28 cases (57.9\%); and brain tissue in 10/11 cases $(90.9 \%)$ (Extended Data Table 3).

We additionally detected SARS-CoV-2 sgRNA across all tissue categories, predominately among early cases $(14 / 17,82.4 \%)$, as well as in plasma, pleural fluid, and vitreous humor (Fig. 1, Extended Data Fig. 2, Supplementary Data 1). sgRNA was also detected in at least one tissue of $61.5 \%$ of mid cases and $42.9 \%$ of late cases, including across three tissue categories in a case at D99 (P20).

We isolated SARS-CoV-2 in cell culture from multiple pulmonary and extrapulmonary tissues, including lung, bronchus, sinus turbinate, heart, mediastinal lymph node, small intestine, and adrenal gland from early cases up to D7 (P19, P27, P32, P37; Supplementary Data 1).

\section{Intra-individual viral variant diversity}

We used HT-SGS to analyze SARS-CoV-2 spike gene variant sequences from a total of 46 tissues in six individuals. In five individuals from the early group, predominant spike sequences were largely identical across tissues. In P27, P19, and P18, no non-synonymous virus genetic diversity was detected in pulmonary and extrapulmonary sites despite a high depth of single-molecule sampling (Extended Data Fig. 3). Thus, virus populations that were relatively 
181 homogeneous had disseminated in these individuals without coding changes in spike. However, 182 we also noted important patterns of intra-individual virus diversity in several patients from the 183 early group. In P27, although all 4,525 inferred spike amino acid sequences were identical, two

184 virus haplotypes, each with a single synonymous substitution, were preferentially detected in extrapulmonary sites including right and left ventricles and mediastinal LN. In P38, we observed 186 clear virus genetic differences between the lung lobes and the brain, with a D80F residue found 187 in $31 / 31$ pulmonary but $0 / 490$ brain sequences and a $\mathrm{G} 1219 \mathrm{~V}$ residue that was restricted to brain 188 minor variants. A similar distinction was observed between sequences from dura mater and other 189 sites in P36, albeit at very low sampling depth $(n=2$ sequences $)$ from dura mater. Overall, these 190 findings suggested no need for alterations in receptor utilization to permit extrapulmonary 191 dissemination of SARS-CoV-2, while also revealing genetic compartmentalization between 192 viruses in the lung lobes and those in extrapulmonary sites, including the brain.

\section{ISH reveals SARS-CoV-2 cellular tropism}

We validated our ddPCR results across all tissue categories via ISH for SARS-CoV-2 196 spike RNA across selected early, mid, and late cases (Supplementary Data 3). Overall, we 197 detected SARS-CoV-2 RNA via ISH in 36 distinct cell types across all sampled organs

198 (Extended Data Table 4, Supplementary Data 3). Spike RNA was detected throughout the 199 respiratory tract in early cases, as well as within the sinus turbinate, trachea, lungs, from late 200 cases (i.e., P33, P20, P42).

The heart contained spike RNA within myocytes, endothelium, and smooth muscle of 202 vessels of both early (P18, P19) and late (P3 \& P42) cases. The pericardium demonstrated a 203 positive signal for spike RNA within fibroblasts of the stroma. Intimal cells of the aorta were 
204 additionally found to contain spike RNA. Mononuclear leukocytes within the lymph node,

205 spleen, and appendix of an early case (P19) contained spike RNA, as did colonic epithelium (Fig $2062)$.

Epithelial cells along the intestinal tract in early cases (P16, P18, P19) contained viral RNA, as well as stratified squamous epithelium of the esophagus. Mononuclear leukocytes were again visualized with SARS-CoV-2 RNA in lymphoid aggregates and the interstitium of the small and large intestine, with infected cells still present in the colon of late cases (P33, P42).

211 Kupffer cells, hepatocytes, and bile duct epithelium within the liver were additionally found to 212 contain spike RNA.

Within the kidney, spike RNA could be visualized within parietal epithelium of

214 Bowman's capsule, collecting duct cells, distal tubule cells, and glomerular endothelium. The 215 adrenal glands contained spike RNA within endocrine cells. Endocrine follicular cells of the 216 thyroid and glandular cells of the pancreas were also positive for spike RNA (Fig. 2). Among 217 reproductive organs, spike RNA was visualized within Leydig and Sertoli cells of the testis, 218 germ cells within the testicular tubules, endometrial gland epithelium, endometrial stromal cells, 219 uterine smooth muscle cells, and stromal cells of the post-menopause ovary (Fig. 2). Myocytes within skeletal muscle contained spike RNA in both early (P18) and late (P20)

221 cases. In addition to the organ-specific cell type infection of SARS-CoV-2, endothelium, 222 muscularis of atrial vessels, and Schwann cells were identified as infected throughout the body, 223 and were similarly positive across early and late cases. Spike RNA was found in neurons, glia and ependyma, as well as endothelium of vessels 225 across all lobes of the brain of early, mid, and late cases. Within the cerebellum specifically, 
226 neurons, Purkinje cells, and endothelium of vasculature also contained spike protein via IHC

227 (Fig. 3).

229 COVID-19 histological findings

The histopathology findings from our cohort were similar to those reported in other case

231 series (Extended Data Fig. 4). All but five cases were considered to have died from COVID-19

232 (Extended Data Table 5), and, of these, 37 (94.5\%) had either acute pneumonia or diffuse

233 alveolar damage at the time of death (Supplementary Data 2). Phases of diffuse alveolar damage

234 showed clear temporal associations, with the exudative phase seen mainly within the first three

235 weeks of infection and the fibrosing phase not seen until after a month of infection (Extended

236 Data Fig. 5). Pulmonary thromboembolic complications, which were also likely related to

237 SARS-CoV-2 infection, with or without infarction, were noted in 10 (23\%) cases. Another

238 finding likely related to SARS-CoV-2 infection included myocardial infiltrates in four cases,

239 including one case of significant myocarditis ${ }^{16}(\mathrm{P} 3)$. Some of the cases of microscopic ischemia

240 appeared to be associated with fibrin-platelet microthrombi, and may therefore be related to

241 COVID-19 thrombotic complications. Within the lymph nodes and spleen, we observed

242 lymphodepletion and both follicular and paracortical hyperplasia.

Outside the lungs, histological changes were mainly related to complications of therapy

244 or preexisting co-morbidities: mainly obesity, diabetes, and hypertension. Five cases had old

245 ischemic myocardial scars and three had coronary artery bypass grafts in place. Given the

246 prevalence of diabetes and obesity in our cohort, it was not surprising to find diabetic

247 nephropathy (10 cases, $23 \%$ ) or steatohepatitis (5 cases, 12\%). One case was known to have

248 chronic hepatitis $\mathrm{C}$ with cirrhosis, but the other cases of advanced hepatic fibrosis were likely 
249 related to fatty liver disease, even if diagnostic features of steatohepatitis were not present.

250 Hepatic necrosis (13 cases, 30\%) and changes consistent with acute kidney injury (17 cases,

$25139 \%$ ) were likely related to hypoxic-ischemic injury in these very ill patients.

252 In the examination of the 11 brains, we found few histopathologic changes, despite the

253 evidence of substantial viral burden. Vascular congestion was an unusual finding that had an

254 unclear etiology and could be related to the hemodynamic changes incurred with infection.

255 Global hypoxic/ischemic change was seen in two cases, one of which was a juvenile (P36) with a

256 seizure disorder who was found to be SARS-CoV-2 positive on hospital admission, but who

257 likely died of seizure complications unrelated to viral infection.

\section{Discussion}

Here we provide the most comprehensive analysis to date of SARS-CoV-2 cellular

261 tropism, quantification, and persistence across the body and brain, in a diverse autopsy cohort

262 collected throughout the first year of the pandemic in the United States. Our focus on short post-

263 mortem intervals, comprehensive approach to tissue collection, and preservation techniques -

264 RNAlater and flash freezing of fresh tissue - allowed us to detect and quantify viral levels with

265 high sensitivity by ddPCR and ISH, as well as culture virus, which are notable differences

266 compared to other studies.

267 We show SARS-CoV-2 disseminates across the human body and brain early in infection 268 at high levels, and provide evidence of virus replication at multiple extrapulmonary sites during 269 the first week following symptom onset. We detected sgRNA in at least one tissue in over half of 270 cases (14/27) beyond D14, suggesting that prolonged viral replication may occur in extra271 pulmonary tissues as late as D99. While others have questioned if extrapulmonary viral presence 
272 is due to either residual blood within the tissue $e^{8,17}$ or cross-contamination from the lungs during

273 tissue procurement ${ }^{8}$, our data rule out both theories. Only 12 cases had detectable SARS-CoV-2

274 RNA in a perimortem plasma sample, and of these only two early cases also had SARS-CoV-2

275 sgRNA in the plasma, which occurred at Ct levels higher than nearly all of their tissues with

276 sgRNA. Therefore, residual blood contamination cannot account for RNA levels within tissues.

277 Furthermore, blood contamination would not account for the SARS-CoV-2 sgRNA or virus

278 isolated from tissues. Contamination of additional tissues during procurement, is likewise ruled

279 out by ISH demonstrating widespread SARS-CoV-2 cellular tropism across the sampled organs,

280 by IHC detecting viral protein in the brain, and by several cases of virus genetic

281 compartmentalization in which spike variant sequences that were abundant in extrapulmonary

282 tissues were rare or undetected in lung samples.

283 Using both ddPCR and sgRNA analysis to inform our selection of tissue for virus

284 isolation and ISH staining allow us to describe a number of novel findings. Others ${ }^{6,8-12,17}$ have

285 previously reported SARS-CoV-2 RNA within the heart, lymph node, small intestine, and

286 adrenal gland. We demonstrate conclusively that SARS-CoV-2 is capable of infecting and

287 replicating within these tissues. Current literature has also reported absent or controversial

288 expression of ACE2 and/or TMPRSS2 in several extrapulmonary tissues, such as the colon,

289 lymphoid tissues, and ocular tissues, calling into question if these tissues can become infected by

290 SARS-CoV-2 $2^{1-3}$. However, we observed high levels of SARS-CoV-2 RNA and evidence of

291 replication within these organs, as well as SARS-CoV-2 RNA via ISH in colonic mucosal

292 epithelium and mononuclear leukocytes within the spleen, thoracic cavity lymph nodes, and GI

293 lymphoid aggregates. We believe these ISH positive cells represent either infection or 
294 phagocytized virus in resident macrophages. Further, we isolated virus from a mediastinal lymph 295 node and ocular tissue from two early cases (P19, P32).

Our use of a single-copy sequencing approach for the SARS-CoV-2 spike allowed us to

297 demonstrate homogeneous virus populations in many tissues, while also revealing informative

298 virus variants in others. Low intra-individual diversity of SARS-CoV-2 sequences has been

299 observed frequently in previous studies ${ }^{18-20}$, and likely relates to the intrinsic mutation rate of the

300 virus as well as lack of early immune pressure to drive virus evolution in new infections. It is

301 important to note that our HT-SGS approach has both a high accuracy and a high sensitivity for 302 minor variants within each sample, making findings of low virus diversity highly reliable ${ }^{21}$. The

303 virus genetic compartmentalization that we observed between pulmonary and extrapulmonary

304 sites in several individuals supports independent replication of the virus at these sites, rather than

305 spillover from one site to another. Importantly, lack of compartmentalization between these sites

306 in other individuals does not rule out independent virus replication, as independently replicating

307 populations may share identical sequences if overall diversity is very low. It was also interesting

308 to note several cases where brain-derived virus spike sequences showed non-synonymous

309 differences relative to sequences from other tissues. These differences may indicate differential

310 selective pressure on spike by antiviral antibodies in brain versus other sites, though further

311 studies will be needed to confirm this speculation.

312 Our results collectively show while that the highest burden of SARS-CoV-2 is in the

313 airways and lung, the virus can disseminate early during infection and infect cells throughout the

314 entire body, including widely throughout the brain. While others have posited this viral

315 dissemination occurs through cell trafficking ${ }^{11}$ due to a reported failure to culture virus from

316 blood $^{3,22}$, our data support an early viremic phase, which seeds the virus throughout the body 
317 following pulmonary infection. Recent work by Jacobs et al. ${ }^{22}$ in which SARS-CoV-2 virions 318 were pelleted and imaged from COVID-19 patient plasma, supports this mechanism of viral 319 dissemination. Although our cohort is primarily made up of severe cases of COVID-19, two 320 early cases had mild respiratory symptoms (P28; fatal pulmonary embolism occurred at home) or 321 no symptoms (P36; diagnosed upon hospitalization for ultimately fatal complications of a 322 comorbidity), yet still had SARS-CoV-2 RNA widely detected across the body, including brain, 323 with detection of sgRNA in multiple compartments. Our findings, therefore, suggest viremia 324 leading to body-wide dissemination, including across the blood-brain barrier, and viral 325 replication can occur early in COVID-19, even in asymptomatic or mild cases. Further, P36 was 326 a juvenile with no evidence of multisystem inflammatory syndrome in children, suggesting 327 infected children without severe COVID-19 can also experience systemic infection with SARS328 CoV-2. locations at which SARS-CoV-2 can persist. While the respiratory tract was the most common 331 location in which SARS-CoV-2 RNA tends to linger, $\geq 50 \%$ of late cases also had persistence in 332 the myocardium, thoracic cavity lymph nodes, tongue, peripheral nerves, ocular tissue, and in all 333 sampled areas of the brain, except the dura mater. Interestingly, despite having much lower 334 levels of SARS-CoV-2 in early cases compared to respiratory tissues, we found similar levels 335 between pulmonary and the extrapulmonary tissue categories in late cases. This less efficient 336 viral clearance in extrapulmonary tissues is perhaps related to a less robust innate and adaptive 337 immune response outside the respiratory tract.

We detected sgRNA in tissue of over $60 \%$ of the cohort. While less definitive than viral 339 culture ${ }^{23,24}$, multiple studies have shown that sgRNA levels correlate with acute infection and can 
340 be detected in respiratory samples of immunocompromised patients experiencing prolonged

341 infection ${ }^{24}$. These data coupled with ISH suggest that SARS-CoV-2 can replicate within tissue

342 for over 3 months after infection in some individuals, with RNA failing to clear from multiple

343 compartments for up to D230. This persistence of viral RNA and sgRNA may represent infection

344 with defective virus, which has been described in persistent infection with measles virus -

345 another single-strand enveloped RNA virus - in cases of subacute sclerosing panencephalitis ${ }^{25}$.

346 The mechanisms contributing to PASC are still being investigated; however, ongoing

347 systemic and local inflammatory responses have been proposed to play a role ${ }^{5}$. Our data provide

348 evidence for delayed viral clearance, but do not support significant inflammation outside of the

349 respiratory tract even among patients who died months after symptom onset. Understanding the

350 mechanisms by which SARS-CoV-2 persists and the cellular and subcellular host responses to

351 viral persistence promises to improve the understanding and clinical management of PASC.

352

353

354

355

356

357

358

359

360

361 


\section{Main References:}

1. Bourgonje, A. R. et al. Angiotensin-converting enzyme 2 (ACE2), SARS-CoV-2 and the pathophysiology of coronavirus disease 2019 (COVID-19). J Pathol. 251(3), 228-248 (2020). https://doi.org/10.1002/path.5471.

2. Salamanna, F., Maglio, M., Landini. M. P., \& Fini, M. Body Localization of ACE-2: On the Trail of the Keyhole of SARS-CoV-2. Front Med (Lausanne). 7, 594495 (2021). https://doi.org/10.3389/fmed.2020.594495.

3. Sridhar, S., \& Nicholls, J. Pathophysiology of infection with SARS-CoV-2-What is known and what remains a mystery. Respirology. 26(7), 652-665 (2021). https://doi.org/10.1111/resp.14091.

4. Al-Aly, Z., Xie, Y., \& Bowe, B. High-dimensional characterization of post-acute sequelae of COVID-19. Nature. 594(7862), 259-264 (2021). https://doi.org/10.1038/s41586-021-03553-9.

5. Crook, H., Raza, S., Nowell, J., Young, M., \& Edison, P. Long covid-mechanisms, risk factors, and management. BMJ. 374, n1648 (2021). https://doi.org/10.1136/bmj.n1648.

6. Puelles, V. G., et al. Multiorgan and Renal Tropism of SARS-CoV-2. N Engl J Med. 383(6), 590-592 (2020). https://doi.org/10.1056/NEJMc2011400.

7. Martines, R. B., et al. Pathology and Pathogenesis of SARS-CoV-2 Associated with Fatal Coronavirus Disease, United States. Emerg Infect Dis. 26(9), 2005-2015 (2020). https://doi.org/10.3201/eid2609.202095.

8. Bhatnagar, J., et al. Evidence of Severe Acute Respiratory Syndrome Coronavirus 2 Replication and Tropism in the Lungs, Airways, and Vascular Endothelium of Patients 
With Fatal Coronavirus Disease 2019: An Autopsy Case Series. J Infect Dis. 223(5), 752764 (2021). https://doi.org/10.1093/infdis/jiab039.

9. Dorward, D. A., et al. Tissue-Specific Immunopathology in Fatal COVID-19. Am J Respir Crit Care Med. 203(2),192-201 (2021). https://doi.org/10.1164/rccm.202008$32650 \mathrm{OC}$

10. Schurink, B., et al. Viral presence and immunopathology in patients with lethal COVID19: a prospective autopsy cohort study. Lancet Microbe. 1(7), e290-e299 (2020). https://doi.org/10.1016/S2666-5247(20)30144-0.

11. Yao, X.H., et al. A cohort autopsy study defines COVID-19 systemic pathogenesis. Cell Res. 31(8), 836-846 (2021). https://doi.org/10.1038/s41422-021-00523-8.

12. Remmelink, M., et al. Unspecific post-mortem findings despite multiorgan viral spread in COVID-19 patients. Crit Care. 24(10), 495 (2020). https://doi.org/10.1186/s13054-02003218-5.

13. Mukerji, S. S., \& Solomon, I. H. What can we learn from brain autopsies in COVID-19? Neurosci Lett. 742, 135528 (2021). https://doi.org/10.1016/j.neulet.2020.135528.

14. Matschke, J., et al. Neuropathology of patients with COVID-19 in Germany: a postmortem case series. Lancet Neurol. 19(11), 919-929 (2020). https://doi.org/10.1016/S1474-4422(20)30308-2.

15. Speranza, E., et al. Single-cell RNA sequencing reveals SARS-CoV-2 infection dynamics in lungs of African green monkeys. Sci Transl Med. 13(578), eabe8146 (2021). https://doi.org/10.1126/scitranslmed.abe8146

16. Vannella, K. M., et al. Evidence of SARS-CoV-2-specific T-cell-mediated myocarditis in a MIS-A case. Front Imunol. Accepted (manuscript ID: 779026). 
17. Desai, N., et al. Temporal and spatial heterogeneity of host response to SARS-CoV-2 pulmonary infection. Nat Commun. 11(1), 6319 (2020). https://doi.org/10.1038/s41467020-20139-7.

18. Tonkin-Hill, G., et al. Patterns of within-host genetic diversity in SARS-CoV-2. Elife. 10, e66857 (2021). https://doi.org/10.7554/eLife.66857.

19. Lythgoe, K. A., et al. SARS-CoV-2 within-host diversity and transmission. Science. 372(6539), eabg0821 (2021). https://doi.org/10.1126/science.abg0821.

20. Valesano, A. L., et al. Temporal dynamics of SARS-CoV-2 mutation accumulation within and across infected hosts. PLoS Pathog. 17(4), e1009499 (2021). https://doi.org/10.1371/journal.ppat.1009499.

21. Ko, S. H., et al. High-throughput, single-copy sequencing reveals SARS-CoV-2 spike variants coincident with mounting humoral immunity during acute COVID-19. PLoS Pathog. 17(4), e1009431 (2021). https://doi.org/10.1371/journal.ppat.1009431.

22. Jacobs, J. L., et al. SARS-CoV-2 Viremia is Associated with COVID-19 Severity and Predicts Clinical Outcomes. Clin Infect Dis. 10, ciab686 (2021). https://doi.org/10.1093/cid/ciab686.

23. Alexandersen, S., Chamings, A., \& Bhatta, T. R. SARS-CoV-2 genomic and subgenomic RNAs in diagnostic samples are not an indicator of active replication. Nat Commun. 11(1), 6059 (2020). https://doi.org/10.1038/s41467-020-19883-7.

24. Binnicker, M. J. Can Testing Predict SARS-CoV-2 Infectivity? The Potential for Certain Methods To Be Surrogates for Replication-Competent Virus. J Clin Microbiol. 59(11), e0046921 (2021). https://doi.org/10.1128/JCM.00469-21. 
430

431

432

433

434

435

436

32

33
25. Sidhu, M. S., et al. Defective measles virus in human subacute sclerosing panencephalitis brain. Virology. 202(20), 631-641 (1994). https://doi.org/10.1006/viro.1994.1384. 

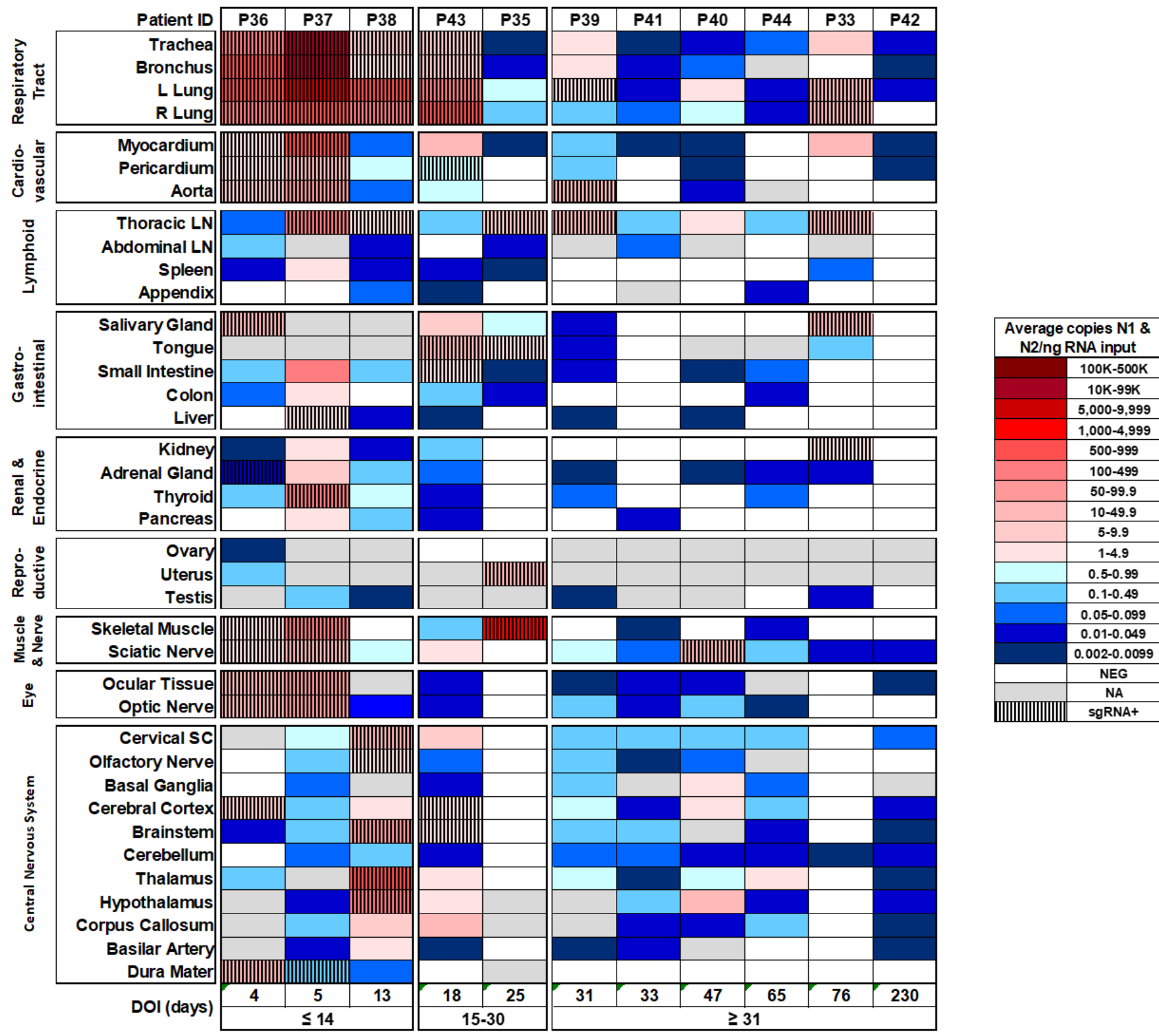

Fig. 1 Distribution, quantification, and replication of SARS-Cov-2 across the human body

439 and brain. The heat map depicts the highest mean quantification of SARS-CoV-2 RNA (N) via

440 ddPCR present within the tissues of eleven COVID-19 autopsy patients who underwent whole

441 body and brain sampling. Patients are aligned from shortest to longest duration of illness (DOI)

442 prior to death, listed at the bottom of the figure, and grouped into early ( $\leq 14$ days), mid (15-30

443 days), and late ( $\geq 31$ days) DOI. Tissues are grouped by tissue category beginning with the 
444 respiratory tract at the top and central nervous system at the bottom. Viral RNA levels range

445 from 0.002 to $500,000 \mathrm{~N}$ gene copies per ng of RNA input, depicted as a gradient from dark blue

446 at the lowest level to dark red at the highest level. Tissues that were also positive for $\operatorname{sgRNA}$ via

447 real-time RT-PCR are shaded with black vertical bars. L/left, LN/lymph node, NA/not acquired,

$448 \mathrm{R} /$ right, SC/spinal cord.

449

450

451

452

453

454

455

456

457

458

459 


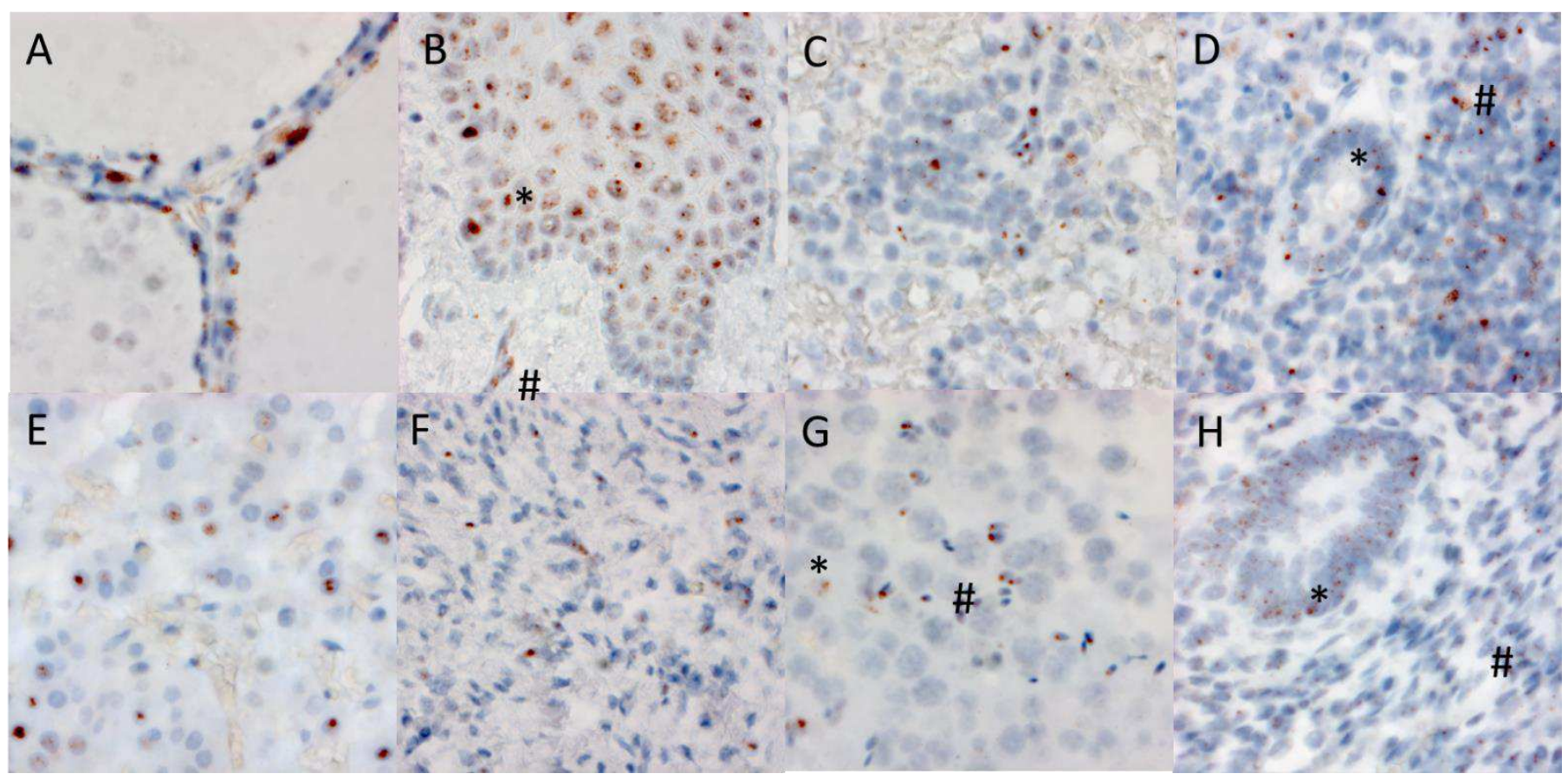

Fig. 2 RNA in situ (RNAscope) detection of SARS-CoV-2 in extrapulmonary tissues.

462 SARS-CoV-2 virus is localized to the Golgi and endoplasmic, peri-nuclear in appearance, in the

463 following organs and cell types (500 X magnifications): A) Thyroid, demonstrating presence of

464 virus within follicular cells. B) Esophagus, demonstrating the presence of virus within the

465 stratified squamous epithelium (*), as well as signal in capillaries within the stroma (\#). C.

466 Spleen, demonstrating the presence of mononuclear lymphoid cells within the white pulp. D)

467 Appendix, demonstrating the presence of virus in both colonic epithelium (*) and mononuclear

468 lymphoid cells in the stroma (\#). E) Adrenal demonstrates virus within endocrine secretory cells

469 of the adrenal gland. F) Ovary demonstrates the presence of virus in stromal cells of the ovary in

470 a post-menopausal ovary. G) Testis demonstrates the presence of virus in both Sertoli cells (*)

471 and maturing germ cells within the seminiferous tubules of the testis (\#). H) Endometrium

472 demonstrates the presence of virus within endometrial gland epithelium $(*)$ and stromal cells (\#),

473 in a pre-menopausal endometrial sample. 


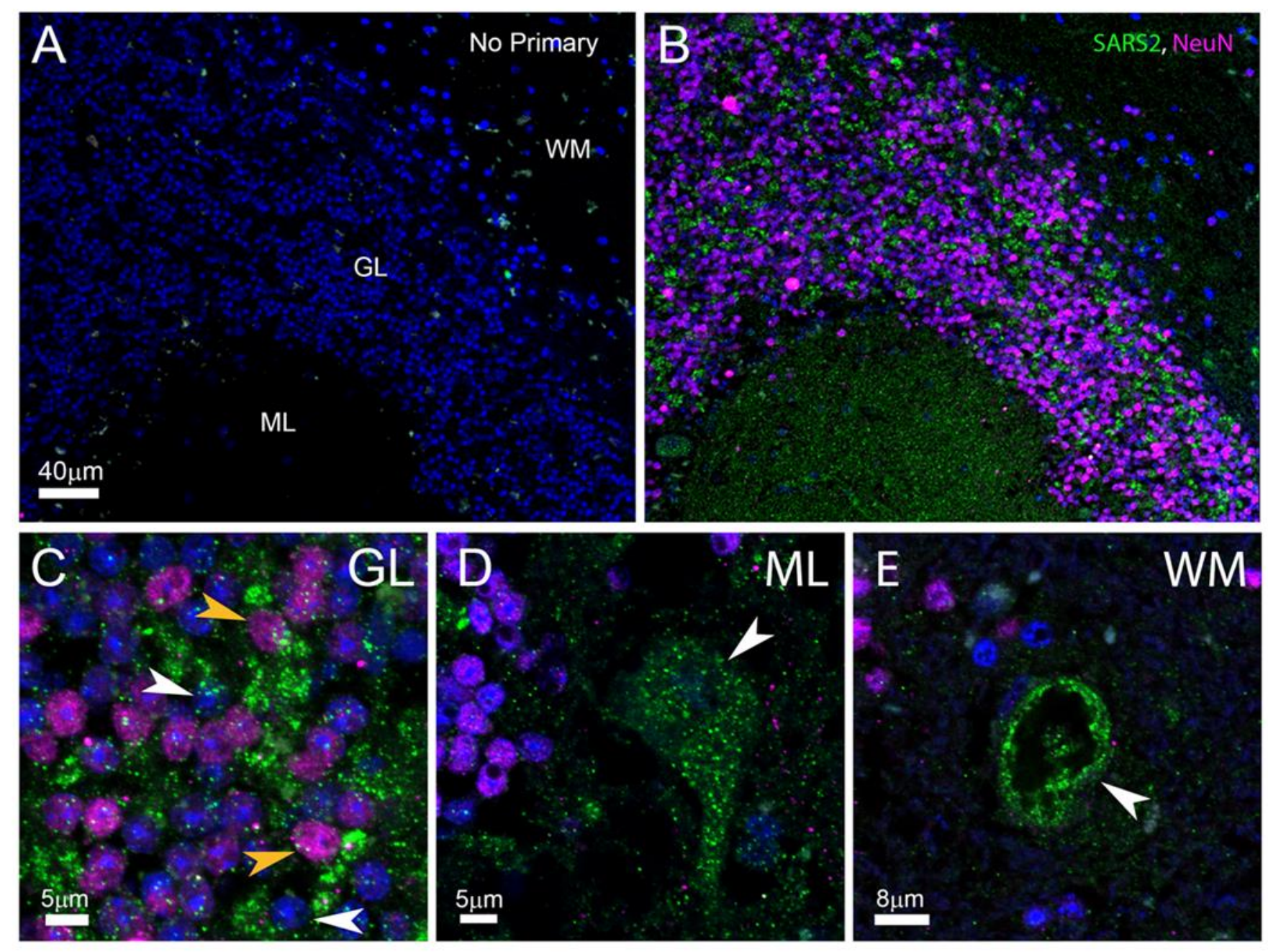

476 Fig. 3 SARS-CoV-2 protein expression in human cerebellum. Low magnification

477 visualization of no-primary control (A) and primary-added adjacent (B) cerebellar sections

478 labeled for SARS-CoV-2 (green) and NeuN (magenta) demonstrate viral-specific protein

479 expression within the tissue. The locations of the molecular layer (ML), granular layer (GL), and

480 white matter (WM) are indicated in (A) and also correspond to (B). Higher magnification images

481 demonstrate cell type-specific infection (C-E). Both NeuN positive neurons (yellow arrows) and

482 other unidentified cells (white arrows) are associated with viral protein in the GL (C). Purkinje

483 cells adjacent to the ML are infected (D, white arrow). In rare instances, blood vessels adjacent 
484 to the GL and WM were associated with viral protein (E, white arrow). The scale bars in $\mathrm{A}$ is 485 also associated with B. All immunofluorescent images were obtained by confocal microscopy. 
Methods:

\section{Autopsies}

Autopsies were performed and tissues were collected as previously described ${ }^{26}$ in the National Cancer Institute's Laboratory of Pathology at the National Institutes of Health Clinical Center

511 following consent of the legal next of kin.

Measurement of IgG and IgM antibodies against Nucleocapsid and Spike protein of SARS-

\section{CoV-2}

Fluid-phase luciferase immunoprecipitation systems (LIPS) assays were used to study IgG and

516 IgM antibody response to SARS-CoV-2. For IgG LIPS measurements, Renilla luciferase-

517 nucleocapsid and Gaussia luciferase-spike protein extracts were employed with protein A/G

518 beads (Protein A/G UltraLink Resin, Thermo Fisher Scientific) as the IgG capture reagent as

519 previously described with microtiter filter plates ${ }^{27}$. For IgM measurements, anti-human IgM goat

520 agarose beads (Sigma) were substituted as the capture reagent using both the microfilter plate

521 and microtube format ${ }^{28}$. The IgM immunoprecipitation assays performed in $1.5 \mathrm{ml}$ microfuge

522 tube format containing $1 \mu \mathrm{l}$ sera or plasma, Renilla luciferase-nucleocapsid (10 million light unit

523 input per tube) or Gaussia luciferase-spike protein (40 million light input per tube) and buffer A

524 (20 mM Tris, $\mathrm{pH} 7.5,150 \mathrm{mM} \mathrm{NaCl}, 5 \mathrm{mM} \mathrm{MgCl}, 0.1 \%$ Triton X-100) to a total volume of 100

$525 \mu$ l. After mixing, the tubes were incubated at room temp for 1 hour. Next $10 \mu$ of the anti-human

$526 \operatorname{IgM}$ agarose bead suspension was added to each tube for additional 60 minutes and tubes were

527 placed on a rotating wheel at $4^{\circ} \mathrm{C}$. The samples were then washed by brief centrifugation to

528 collect the bead pellet at room temperature 3 times with $1.5 \mathrm{ml}$ Buffer A and once with $1.5 \mathrm{ml}$ of

529 PBS. After the final wash, the beads were mixed with coelenterazine substrate $(100 \mu l)$ and light 
530 units measured in a tube luminometer. Known seronegative and seropositive samples for IgG and

531 IgM antibodies against nucleocapsid and spike proteins were used for assigning seropositive cut-

532 off values and for standardization.

\section{SARS-CoV-2 RNA quantification of tissues and body fluids}

535 Total RNA was extracted from RNAlater (Invitrogen)-preserved tissues and body fluids

536 collected at autopsy using the RNeasy Mini, RNeasy Fibrous Tissue Mini, RNeasy Lipid Tissue

537 Mini Kit, and QIAamp Viral RNA Mini Kits (Qiagen) according to the manufacturer's protocols.

538 Upstream tissue processing and subsequent RNA quantification have been previously

539 described $^{26}$. The QX200 AutoDG Droplet Digital PCR System (Bio-Rad) was used to detect and

540 quantify SARS-CoV-2 RNA in technical replicates of $5.5 \mathrm{uL}$ RNA for fluids and up to $550 \mathrm{ng}$

541 RNA for tissues as previously described ${ }^{26}$. Results were then normalized to copies of N1, N2,

542 and RP per mL of sample input for fluids and per ng of RNA concentration input for tissues. For

543 samples to be considered positive for SARS-CoV-2 N1 or N2 genes, they needed to mean the

544 manufacturer's limit of detection of $\geq 0.1$ copies $/ \mu \mathrm{L}$ and $\geq 2$ positive droplets per well. Over 60

545 control autopsy tissues from uninfected patients, representing all organs collected for COVID-19

546 autopsy cases, were used to validate the manufacturer's EUA published LOD for nasopharyngeal

547 swabs for tissues (Extended Data Table 8). ddPCR data for P3 ${ }^{16}$ as well as a portion of tissues

548 from the oral cavity ${ }^{26}$ have been previously reported.

\section{sgRNA analysis of ddPCR positive tissues}

551 Tissues that tested positive for one or both SARS-CoV-2 N gene targets via ddPCR had RNA

552 submitted for sgRNA analysis. Briefly, five $\mu$ RNA was used in a one-step real-time RT-PCR 
553 assay to sgRNA (forward primer 5'- CGATCTCTTGTAGATCTGTTCTC-3'; reverse primer 5'-

554 ATATTGCAGCAGTACGCACACA-3'; probe 5'-FAM-

555 ACACTAGCCATCCTTACTGCGCTTCG-ZEN-IBHQ-3' ${ }^{29}$ using the Rotor-Gene probe kit

556 (Qiagen) according to instructions of the manufacturer. In each run, standard dilutions of counted

557 RNA standards were run in parallel to calculate copy numbers in the samples. The limit of

558 detection for this assay was determined to be <40 Cq (Supplemental Data 1) using 40 control

559 autopsy tissues from uninfected patients, representing all organs collected for COVID-19

560 autopsy cases.

561

562 Viral isolation from select postmortem tissues

563 Select tissues with high viral RNA levels via ddPCR and sgRNA PCR measuring at or below a

$56430 \mathrm{Cq}$ underwent virus isolation to prove the presence of infectious virus. Virus isolation was

565 performed on tissues by homogenizing the tissue in 1ml DMEM and inoculating Vero E6 cells in 566 a 24-well plate with $250 \mu \mathrm{l}$ of cleared homogenate and a 1:10 dilution thereof. Plates were

567 centrifuged for 30 minutes at $1000 \mathrm{rpm}$ and incubated for 30 minutes at $37^{\circ} \mathrm{C}$ and $5 \% \mathrm{CO} 2$. The

568 inoculum was then removed and replaced with $500 \mu 1 \mathrm{DMEM}$ containing $2 \% \mathrm{FBS}, 50 \mathrm{U} / \mathrm{ml}$

569 penicillin and $50 \mu \mathrm{g} / \mathrm{ml}$ streptomycin. Six days after inoculation, cytopathic effect (CPE) was

570 scored. A blind passage of samples where no CPE was present, was performed according to the

571 same method. Supernatants from plates with CPE present were analyzed via PCR for SARS-

572 CoV-2 to rule out other causes of CPE.

573

$574 \quad$ Virus Sequencing Methods 
Patients with duration of illness $\leq 7 \mathrm{~d}$ (P27, P19) and 8-14 d (P18) with multiple body site

576

577

578

579

580

581

582

583

584

585

586

587

588

589

590

591

592

593

594

595

596

597

tissues containing sgRNA levels $\leq 31 \mathrm{Cq}$ value were selected for high throughput, single-genome amplification and sequencing (HT-SGS) as previously described ${ }^{21}$. Presence of variants of SARS-CoV-2 were analyzed within and between tissues.

\section{SARS-CoV-2 RNA in situ hybridization}

Chromogenic in situ detection was performed using the manual RNAScope 2.5 HD assay (Cat\# 322310, Advanced Cell Diagnostics, Hayward, CA) with a modified pretreatment protocol.

Briefly, formalin-fixed and paraffin-embedded (FFPE) tissue sections were cut at $7 \mu \mathrm{m}$, air dried overnight, and baked for $2 \mathrm{hrs}$ at $60^{\circ} \mathrm{C}$. The FFPE tissue sections were deparaffinized, dehydrated, and then treated with pretreat 1 for $10 \mathrm{~min}$ at room temperature. The slides were boiled with pretreatment reagent for $15 \mathrm{~min}$, digested with protease at $40^{\circ} \mathrm{C}$ for $10 \mathrm{~min}$, then hybridized for 2 hours at $40^{\circ} \mathrm{C}$ with probe- $V$-nCov2019-S (Cat\# 848561, Advanced Cell Diagnostics). In addition, probe-Hs-PPIB (Cat\# 313901, Advanced Cell Diagnostics) and probedapB (Cat\# 310043, Advanced Cell Diagnostics) were used as a positive and negative control, respectively. Subsequent amplification was done according to the original protocol. Detection of specific probe binding sites were visualized with RNAScope 2.5 HD Reagent kit-brown chromogenic labels (Advanced Cell Diagnostics). The slides were counterstained with hematoxylin and cover-slipped.

\section{SARS-CoV-2 immunohistochemistry}

FFPE cerebellar sections were deparaffinized, rehydrated and subject to $0.01 \mathrm{M}$ Citrate buffer antigen retrieval for $20 \mathrm{~min}$ at $120^{\circ} \mathrm{C}$. Slides were incubated in $0.1 \%$ TritonX100 in PBS for 
598 30min, washed extensively with PBS and fresh True Black Plus® solution (1:40, Cat\#23014, 599 Biotium) applied for $7 \mathrm{~min}$. Following PBS wash, blocking serum (5\% normal donkey 600 serum/0.3M glycine) was applied for 30min. Primary antibodies against SARS-CoV-2 NP1 601 (1:250, custom made) and NeuN (1:200, Cat\#MAB377, Chemicon) were diluted in blocking 602 serum and applied to slides overnight at $4^{\circ} \mathrm{C}$. Species-specific secondary conjugates (1:500, 603 Cat\#A32790 and \#A32744, ThermoFisher) were applied for 1 hr at RT. Hoescht 33342 applied 604 for 10min (1:2000, Cat\#H3570, ThermoFisher) labeled nuclei. Slides were cover-slipped with 605 Prolong Gold (Cat\#P36930, ThermoFisher).

606

607 Data Availability

608 The datasets that support the findings of this study are available in Supplementary Data 1, 2 and 609 3. Sequence data described in this manuscript have been deposited (database accession numbers $610 \mathrm{XXXX).} \mathrm{The} \mathrm{bioinformatic} \mathrm{pipeline} \mathrm{for} \mathrm{HT-SGS} \mathrm{data} \mathrm{analysis} \mathrm{has} \mathrm{been} \mathrm{deposited}$

611 (https://github.com/niaid/UMI-pacbio-pipeline). ISH images from our cohort as well as positive 612 and negative controls are available in Supplementary Data 3, which is available at 613 https://halo.cancer.gov, Authentication method: NIH, username: halocancernci@ gmail.com, 614 password: covid19N!H.

615

616 Methods References:

617 26. Huang, N., et al. SARS-CoV-2 infection of the oral cavity and saliva. Nat Med. 27, 892618 903 (2021). https://doi.org/10.1038/s41591-021-01296-8.

619 27. Burbelo, P. D., et al. Sensitivity in Detection of Antibodies to Nucleocapsid and Spike

620 Proteins of Severe Acute Respiratory Syndrome Coronavirus 2 in Patients With 
Coronavirus Disease 2019. J Infect Dis. 222(2), 206-213 (2020). https://doi.org/10.1093/infdis/jiaa273.

28. Burbelo, P. D., Goldman, R., \& Mattson, T. L. A simplified immunoprecipitation method for quantitatively measuring antibody responses in clinical sera samples by using mammalian-produced Renilla luciferase-antigen fusion proteins. BMC Biotechnol. 5, 22 (2005). https://doi.org/10.1186/1472-6750-5-22.

29. Wölfel R., et al. Virological assessment of hospitalized patients with COVID-19. Nature. 581(7809), 465-469 (2020). https://doi.org/10.1038/s41586-020-2196-х.

\section{Acknowledgements:}

This study was funded and supported by the Intramural Research Program of the National Institutes of Health, Clinical Center, National Institute of Dental and Craniofacial Research, and National Institute of Allergy and Infectious Diseases.

This research was made possible through the NIH Medical Research Scholars Program, a public-private partnership supported jointly by the NIH and contributions to the Foundation for the NIH from the Doris Duke Charitable Foundation, Genentech, the American Association for Dental Research, and the Colgate-Palmolive Company.

\section{$\underline{\text { NIH COVID-19 Autopsy Consortium }}$}

Daniel S. Chertow ${ }^{1,2}$, Kevin M. Vannella ${ }^{1,2}$, Sydney R. Stein ${ }^{1,2}$, Marcos J. Ramos-Benitez ${ }^{1,2,4}$, Andrew P. Platt ${ }^{1,2}$, James M. Dickey ${ }^{1,2}$, Ashley L. Babyak ${ }^{1,2}$, Luis J. Perez Valencia ${ }^{1,2}$, Sabrina

C. Ramelli ${ }^{3}$, Shelly J. Curran ${ }^{3}$, Mary E. Richert ${ }^{3}$, David E. Kleiner ${ }^{5}$, Stephen M. Hewitt ${ }^{5}$, Martha Quezado $^{5}$, Willie J. Young ${ }^{5}$, Sarah P. Young ${ }^{5}$, Billel Gasmi ${ }^{5}$, Michelly Sampaio De Melo ${ }^{5}$, 
644 Sabina Desar ${ }^{5}$, Saber Tadros ${ }^{5}$, Nadia Nasir ${ }^{5}$, Xueting Jin ${ }^{5}$, Sharika Rajan ${ }^{5}$, Esra Dikoglu ${ }^{5}$, Neval 645 Ozkaya $^{5}$, Kris Ylaya ${ }^{5}$, Joon-Yong Chung ${ }^{5}$, Stefania Pittaluga ${ }^{5}$, Grace Smith $^{5}$, Elizabeth R.

646 Emanuel $^{6}$, Brian L. Kelsall ${ }^{6}$, Justin A. Olivera ${ }^{7}$, Megan Blawas ${ }^{7}$, Robert A. Star ${ }^{7}$, Alison

647 Grazioli $^{8}$, Nicole Hays ${ }^{9}$, Madeleine Purcell ${ }^{9}$, Shreya Singireddy ${ }^{9}$, Jocelyn $\mathrm{Wu}^{9}$, Katherine Raja ${ }^{9}$, 648 Ryan Curto ${ }^{9}$, Jean E. Chung ${ }^{10}$, Amy J. Borth ${ }^{10}$, Kimberly A. Bowers ${ }^{10}$, Anne M. Weichold ${ }^{10}$, 649 Paula A. Minor ${ }^{10}$, Mir Ahmad N. Moshref ${ }^{10}$, Emily E. Kelly ${ }^{10}$, Mohammad M. Sajadi ${ }^{11,12}$, Kapil 650 K. Saharia ${ }^{11,12}$, Daniel L. Herr ${ }^{13}$, Thomas M. Scalea ${ }^{14}$, Douglas Tran $^{15}$, Ronson J. Madathil ${ }^{15}$, 651 Siamak Dahi ${ }^{15}$, Kristopher B. Deatrick ${ }^{15}$, Eric M. Krause ${ }^{16}$, Joseph Rabin ${ }^{17}$, Joseph A. Herrold ${ }^{18}$, 652 Ali Tabatabai ${ }^{18}$, Eric S. Hochberg ${ }^{18}$, Christopher R. Cornachione ${ }^{18}$, Andrea R. Levine ${ }^{18}$, Justin E. 653 Richards $^{19}$, John Elder ${ }^{20}$, Allen P. Burke ${ }^{20}$, Michael A. Mazzeffi ${ }^{21}$, Robert H. Christenson ${ }^{22}$, 654 Zackary A. Chancer ${ }^{23}$, Mustafa Abdulmahdi ${ }^{24}$, Sabrina Sopha ${ }^{24}$, Tyler Goldberg ${ }^{24}$, Shahabuddin 655 Soherwardi $^{25}$, Yashvir Sangwan ${ }^{26}$, Michael T. McCurdy ${ }^{27,12}$, Kristen Sudano ${ }^{27}$, Diane Blume ${ }^{27}$, 656 Bethany Radin ${ }^{27}$, Madhat Arnouk ${ }^{27}$, James W. Eagan $\mathrm{Jr}^{28}$, Robert Palermo ${ }^{29}$, Anthony D. 657 Harris $^{30}$

Affiliations:

1. Emerging Pathogens Section, Department of Critical Care Medicine, Clinical Center, 661 National Institutes of Health, Bethesda, MD, USA

2. Laboratory of Immunoregulation, National Institute of Allergy and Infectious Diseases, Bethesda, MD, USA

3. Critical Care Medicine Department, Clinical Center, National Institutes of Health, Bethesda, MD, USA 
4. Postdoctoral Research Associate Training Program, National Institute of General Medical Sciences, National Institutes of Health, Bethesda, MD, USA

5. Laboratory of Pathology, Center for Cancer Research, National Cancer Institute, National Institutes of Health, Bethesda, MD, USA

6. Mucosal Immunobiology Section, Laboratory of Molecular Immunology, National Institute of Allergy and Infectious Diseases, National Institutes of Health, Bethesda, MD, USA

7. Renal Diagnostics and Therapeutics Unit, Kidney Diseases Branch, National Institute of Diabetes and Digestive and Kidney Diseases, National Institutes of Health, Bethesda, MD, USA

8. Kidney Disease Section, Kidney Diseases Branch, National Institute of Diabetes and Digestive and Kidney Diseases, National Institutes of Health, Bethesda, MD, USA

9. University of Maryland School of Medicine, Baltimore, MD, USA

10. University of Maryland Medical Center, Baltimore, MD, USA

11. Institute of Human Virology, University of Maryland School of Medicine, Baltimore, MD, USA

12. Department of Medicine, Division of Pulmonary and Critical Care Medicine, University of Maryland School of Medicine, Baltimore, MD, USA

13. R Adams Cowley Shock Trauma Center, Department of Medicine and Program in Trauma, University of Maryland School of Medicine, Baltimore, MD, USA

14. Department of Shock Trauma Critical Care, University of Maryland School of Medicine, Baltimore, MD, USA 
15. Department of Surgery, Division of Cardiac Surgery, University of Maryland School of Medicine, Baltimore, MD, USA

16. Department of Surgery, Division of Thoracic Surgery, University of Maryland School of Medicine, Baltimore, MD, USA

17. R Adams Cowley Shock Trauma Center, Department of Surgery and Program in Trauma, University of Maryland School of Medicine, Baltimore, MD, USA

18. Department of Medicine, Division of Infectious Disease, University of Maryland School of Medicine, Baltimore, MD, USA

19. Department of Anesthesiology, Division of Critical Care Medicine, University of Maryland School of Medicine, Baltimore, MD, USA

20. Department of Autopsy and Thoracic Pathology, University of Maryland School of Medicine, Baltimore, MD, USA

21. Department of Anesthesiology and Critical Care Medicine, George Washington School of Medicine and Health Sciences, Washington, DC USA

22. Department of Laboratory Science, University of Maryland School of Medicine, Baltimore, MD, USA

23. Department of Anesthesiology, University of Southern California Keck School of Medicine, Los Angeles, CA, USA

24. Critical Care Medicine, University of Maryland Baltimore Washington Medical Center, Glen Burnie, MD, USA

25. Hospitalist Department, TidalHealth Peninsula Regional, Salisbury, MD, USA

26. Department of Interventional Pulmonology, TidalHealth Peninsula Regional, Salisbury, MD, USA 
27. Division of Critical Care Medicine, Department of Medicine, University of Maryland St. Joseph Medical Center, Towson, MD, USA

28. Department of Pathology, University of Maryland, St. Joseph Medical Center, Towson, MD, USA

29. Department of Pathology, Greater Baltimore Medical Center, Townson, MD, USA

30. Department of Epidemiology and Public Health, University of Maryland School of Medicine, Baltimore, MD, USA

\section{$\underline{\text { Author Contributions }}$}

DSC, KMV, SRS, MJRB, ALB, LJPV, AG, DLH, SMH \& DEK contributed to the study design and protocols for autopsy procurement. APP, JMD, MER, AG, NH, MP, SS, JW, KR, RC, JEC, AJB, KAB, AMW, PAM, MANM, EEK, MMS, KKS, DLH, TMS, DT, RJM, SD, KBD, EMK, JR, JAH, AT, ESH, CRC, ARL, JER, JE, APB, MAM, RHC, ZAC, MA, SS, TG, SS, YS, MTM, KS, DB, BR, MA, JWE Jr, RP, and ADH provided care for, recruited, collected samples from, and/or procured medical records for the patients in this study. DEK, SMH, MQ, WJY, SPY, BG, MSDM, SD, ST, NN, XJ, SR, ED, NO, KY, JYC, SP, and GS conducted the autopsies and/or histological and ISH analysis. SRS, MJRB, APP, JMD, ALB, LJPV, SCR, SJC, ERE, BLK, JAO, MB, and RAS assisted with procurement and preservation of autopsy specimens. SRS with assistance from SCR and JMD performed RNA extraction, ddPCR, and data analysis. MS, CKY, VJM, and EDW performed and analyzed data for sgRNA RT-PCR. CWW and KEP conducted IHC on cerebellum. PDB and JIC measured antibody responses to SARS-CoV-2 in perimortem plasma samples. SHK, FB, and EAB performed viral sequencing. SRS drafted the manuscript with critical input from DSC, KMV, SMH, DEK, SCR, APP, MJRB, EDW, VJM, AG, DLH, 
734 KKS, MMS MTM, PDB, JIC, CWW, KEP, and SJC. All authors approved the submitted version

735 of the manuscript.

736 Competing Interests:

737 The authors declare no competing or conflict of interest.

738 Additional Information:

739 Supplementary information is available for this paper.

740 Correspondence and requests for materials should be addressed to DSC.

741

742

743

744

745

746

747

748 


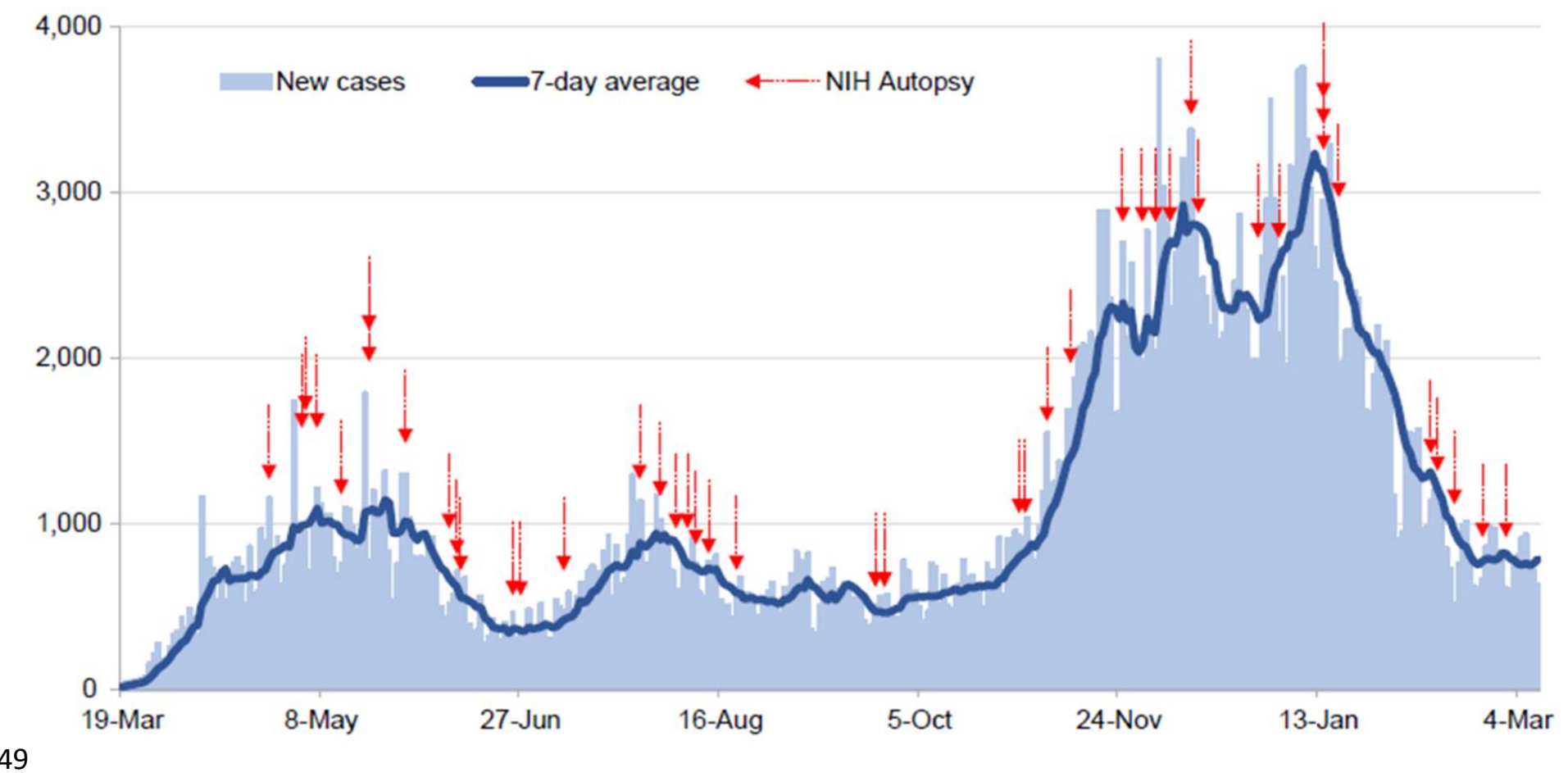

750 Extended Data Fig. 1 Autopsy procurement relative to Maryland COVID-19 cases, March

751 19th, 2020 to March 9th, 2021. Daily COVID-19 reported cases for Maryland (light blue bars)

752 with 7-day average (dark blue line) with timing of autopsies (red arrows).

753

754

755

756

757

758

759

760

761

762 


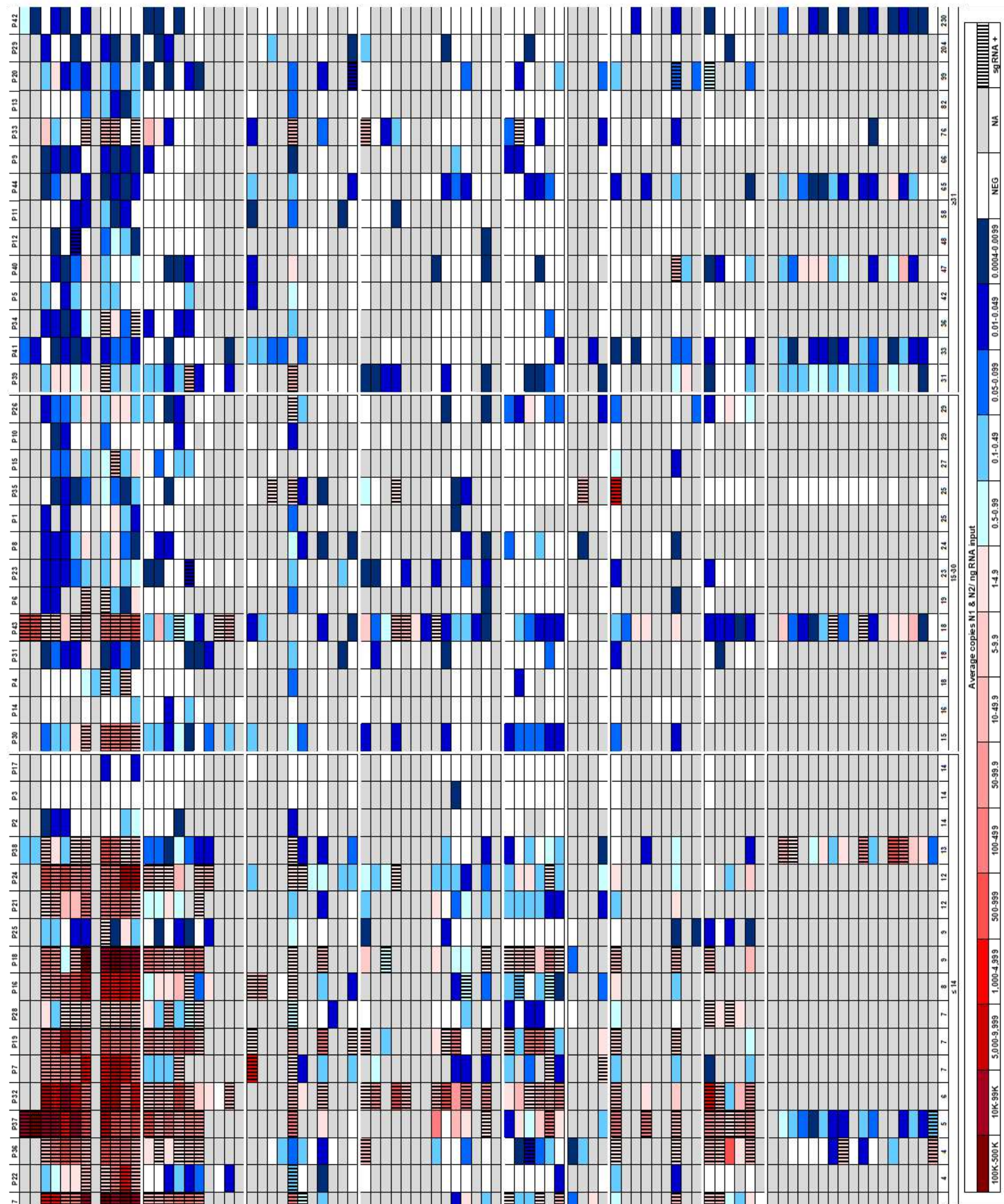


764 Extended Data Fig. 2 Distribution, quantification, and replication of SARS-CoV-2 across the

765 body and brain over time. The heat map depicts the highest average quantification of SARS-

766 CoV-2 RNA (N) via ddPCR present within all sampled tissues of 44 autopsy cases. Patients are

767 aligned from shortest to longest duration of illness (DOI) prior to death, listed at the bottom of

768 the figure, and grouped into early (0-14 d), mid (15-30 d), and late ( $\geq 31 \mathrm{~d})$ DOI. Tissues are

769 grouped by body system beginning with the respiratory tract at the top and CNS at the bottom.

770 Viral RNA levels range from 0.0004 to 500,000 copies per ng of RNA input, depicted as a

771 gradient from dark blue at the lowest level to dark red at the highest level. Tissues that were also

772 positive for sgRNA via real-time RT-PCR are shaded with black vertical bars.

773

774

775

776

777

778

779

780

781

782

783

784

785

786 
a

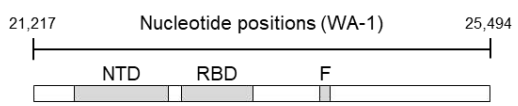

Abdominal Aorta $(n=56$ sequences $)$

L-Inferior Lobe ( $n=815$ sequences)

|||| $\mid$

L-Superior Lobe $(n=321$ sequences $)$

Proximal Trachea $(n=157$ sequences $)$

R-Inferior Lobe ( $n=775$ sequences $)$

R-Middle Lobe ( $n=771$ sequences)

R-Superior Lobe ( $n=970$ sequences)

| |

Thoracic-Aorta ( $n=1$ sequence)

\begin{tabular}{c|l} 
D & Synonymous mutation \\
614 & Non-synonymous mutation (global) \\
G & Non-synonymous mutation (local)
\end{tabular}

C

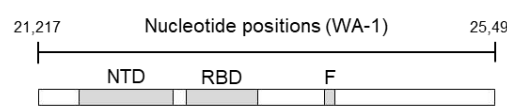

Abdominal-Aorta ( $n=14$ sequences)

$\underset{L-\text { Inferior Lobe }(n=521 \text { sequences })}{||}$

$\longrightarrow$ L $\perp 1 \square$

L-Superior Lobe ( $n=282$ sequences)

\begin{tabular}{|l|l|l|}
\hline & $\mid$
\end{tabular}

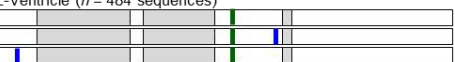

Mediastinal-LN ( $n=840$ sequences)

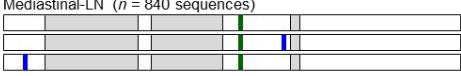

Proximal-Trachea ( $n=204$ sequences $)$

\begin{tabular}{|l|l|l|l|l|}
\hline & & $\mid$ & & \\
\hline \hline & & & & \\
\hline
\end{tabular}

R-Inferior Lobe ( $n=908$ sequences)

R-Middle Lobe ( $n=246$ sequences)

\begin{tabular}{|l|l|l|l|l|l|}
\hline & & & & & \\
\hline \hline & & $\mid$ & I & $\mid$ & \\
\hline
\end{tabular}

R-Superior Lobe ( $n=868$ sequence)

R-Ventricle ( $n=158$ sequences)

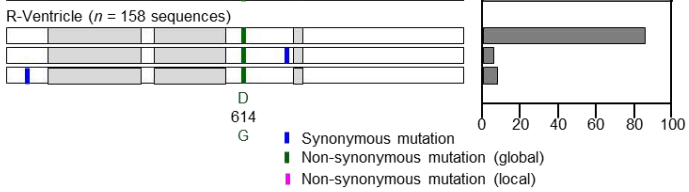

e

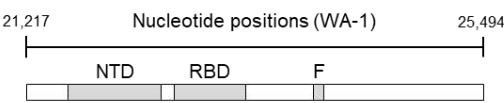

Abdominal Aorta ( $n=11$ sequences)

Pericardium ( $n=5$ sequences)

Pericardium ( $n=5$ sequences $)$
Distal Trachea $(n=17$ sequences $)$

$\mid \frac{|| 17 \text { sequences })}{||}$

Proximal Trachea ( $n=161$ sequences)

\begin{tabular}{|l|l|}
\hline & \\
\hline & \\
\hline
\end{tabular}

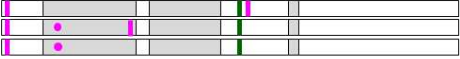

Dura Mater ( $n=2$ sequences)

R-Bronchus ( $n=214$ sequences)

-Bronchus ( $n=263$ sequences)

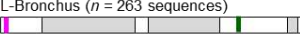

R-Inferior Lobe $(n=10$ sequences)

L-Inferior Lobe $(n=326$ sequences $)$

R-Middle Lobe ( $n=2$ sequences)

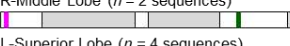

L-Superior Lobe $(n=4$ sequences $)$

R-Superior Lobe ( $n=116$ sequences)

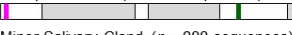

Minor Salivary Gland $(n=288$ sequences)

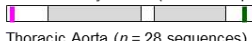

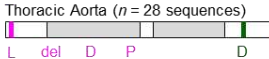

$\begin{array}{ccccccc}L & \text { del } & D & P & & D & P \\ 5 & F & 178 & 295 & & 614 & 621\end{array}$

F $140 \mathrm{~N} S$

$G$ S

I Synonymous mutation

I Non-synonymous mutation (global)

$\%$ of

single genomes

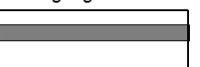

7

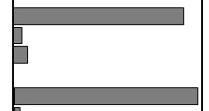

d

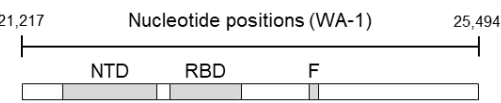

$\%$ of

Thoracic-Aorta ( $n=171$ sequences)

| I II I I

R-Superior Lobe ( $n=521$ sequences)

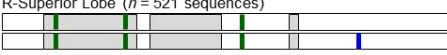

R-Middle Lobe $(n=767$ sequences $)$

R | |

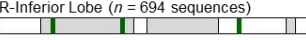

L-Adrenal-Gland( $n=74$ sequences)

L-Inferior Lobe ( $n=9$ sequences)

(

Proximal-Trachea ( $n=558$ sequence)

Pericardium ( $n=168$ sequences)

L-Superior Lobe $(n=274$ sequent

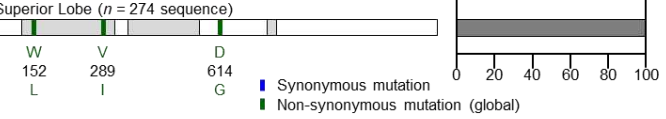

Non-synonymous mutan (global)

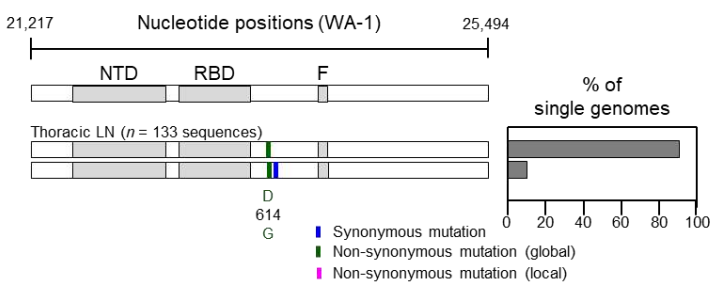

$\%$ of single genomes

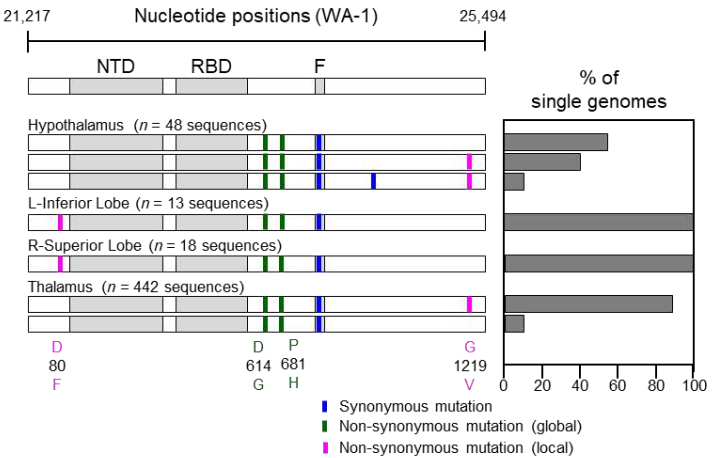


788 Extended Data Figure 3: Analysis of SARS-CoV-2 genetic diversity across body

789 compartments in patients. (a) P18, (b) P19, (c) P27, (d) P33, (e) P36, (f) P38. Haplotype

790 diagrams (left) show SARS-CoV-2 spike single genome sequences detected in multiple organs.

791 Spike NH2-terminal domain (NTD), receptor-binding domain (RBD), and furin cleavage site (F)

792 regions are shaded grey, and remaining regions of the spike are shaded white. Ticks with

793 different colors indicate mutations relative to the WA-1 reference sequence; green indicates non-

794 synonymous differences from WA-1 detected in all sequences in the individual; blue indicates

795 synonymous mutations detected variably within the individual, and pink indicates non-

796 synonymous mutations detected variably within the individual. Bar graphs (right) show the

797 percentage of all single genome sequences in the sample matching each haplotype.

798

799

800

801

802

803

804

805

806

807

808

809

810 


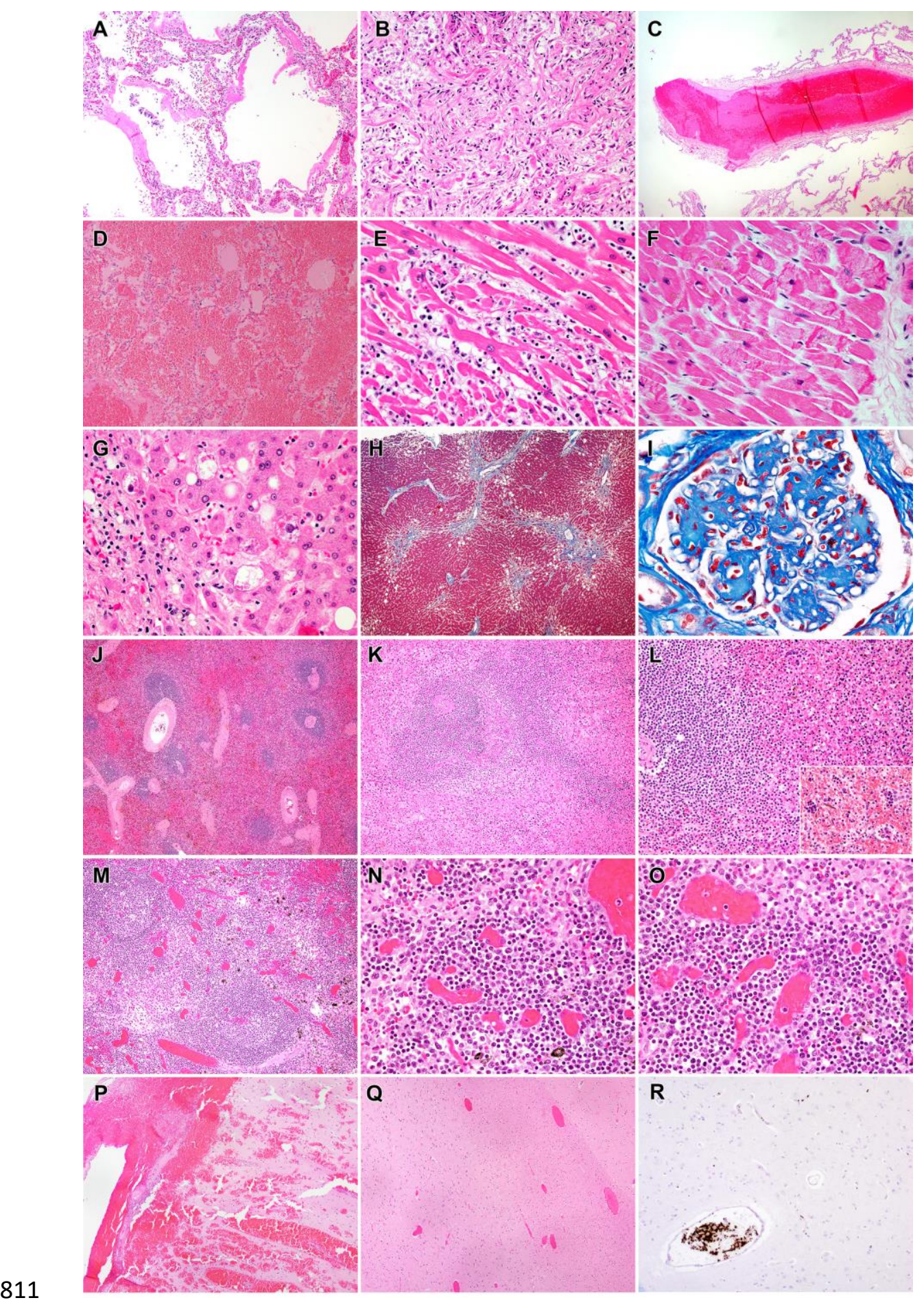

812 Extended Data Fig. 4 Representative findings in patients in the COVID-19 cohort. A. Lung,

813 Subject P22. Exudative phase diffuse alveolar damage with hyaline membranes and mild

814 interstitial inflammation (H\&E, 100x). B. Lung, Subject P26. Proliferative phase diffuse alveolar 
815 damage and sparse inflammation. (H\&E, 200x). C. Lung, Subject P22. Organizing thrombus in 816 medium sized pulmonary artery. (H\&E, 40x). D. Lung, Subject P28. Diffuse pulmonary

817 hemorrhage. (H\&E, 100x). E. Heart, Subject P3. Active lymphocytic myocarditis with

818 cardiomyocyte necrosis. (H\&E, 400x). F. Heart, Subject P38. Microscopic focus of bland

819 myocardial contraction band necrosis. (H\&E, 400x). G. Liver, Subject P41. Steatohepatitis with

820 mild steatosis and scattered ballooned hepatocytes. (H\&E, 400x), H. Liver, Subject P41. Focal

821 bridging fibrosis involving central hepatic veins. (Masson trichrome, 40x). I. Kidney, Subject

822 P16. Nodular glomerulosclerosis. (Masson trichrome, 600x). J. Spleen, Subject P16. Preservation

823 of white pulp and congestion (H\&E, 40x) K. Spleen, Subject P14. Lymphoid depletion of white

824 pulp with proteinaceous material and red pulp congestion. (H\&E, 100x) L. Spleen, Subject P34.

825 Relative preservation of white pulp with extramedullary hematopoiesis (inset) in red pulp (H\&E,

826 200x) M. Lymph node, Subject P25. Follicular hyperplasia with well-defined follicles. (H\&E, )

827 N. Lymph node, Subject P25. Marked plasmacytosis in the medullary cord. (H\&E, 400x) O.

828 Lymph node, Subject P25. Marked plasmacytosis and sinus histiocytosis. (H\&E, 400x) P. Brain,

829 Subject P35, Focal subarachnoid and intraparenchymal hemorrhage. (H\&E, 40x) Q. Brain,

830 Subject P44, Vascular congestion. (H\&E, 40x) R. Brain, Subject P43, Intravascular platelet

831 aggregates. (anti-CD61 stain, 100x)

832

833

834

835

836

837 


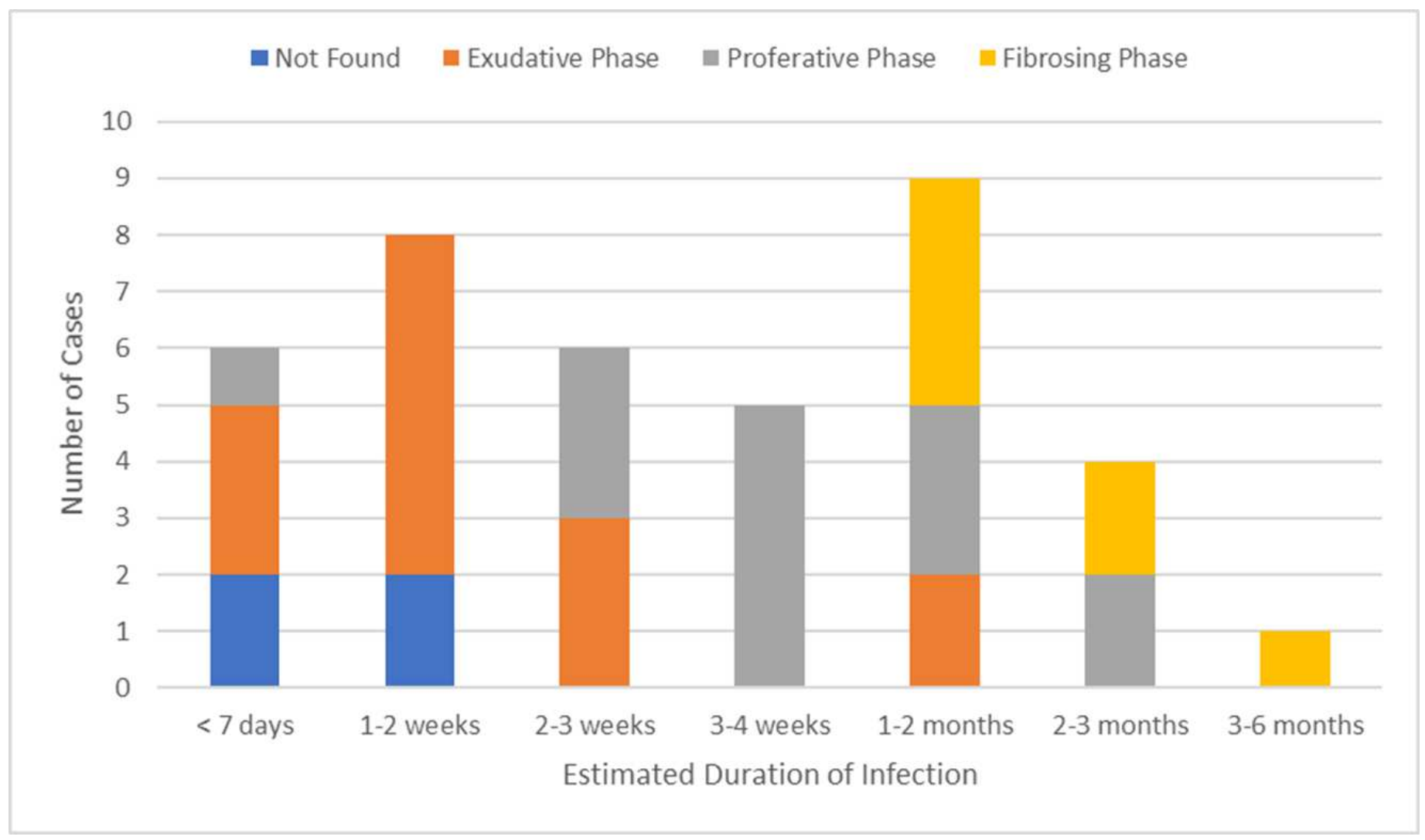

839 Extended Data Fig. 5 Temporal association of diffuse alveolar damage in patients dying

840 from COVID-19. Number of autopsy cases with stages of diffuse alveolar damage via

841 histopathologic analysis by duration of illness. Early time points mainly show the initial

842 exudative phase of diffuse alveolar damage, while patients dying after prolonged illness are more

843 likely to show organizing or fibrosing stages.

844 
a

\begin{tabular}{|c|c|}
\hline$\overline{\text { Age (years) }}$ & $(n=44)$ \\
\hline Mean (Min, Max) & $59.2(6,91)$ \\
\hline Age by group (years) & $n(\%)$ \\
\hline $0-17$ & $1(2.3)$ \\
\hline $18-24$ & $1(2.3)$ \\
\hline $25-34$ & $2(4.5)$ \\
\hline $35-44$ & $6(13.6)$ \\
\hline $45-54$ & $4(9.1)$ \\
\hline $55-64$ & $11(25.0)$ \\
\hline $65-74$ & $11(25.0)$ \\
\hline $75-84$ & $5(11.4)$ \\
\hline$\geq 85$ & $3(6.8)$ \\
\hline \multicolumn{2}{|l|}{ Sex } \\
\hline Male & $30(68.2)$ \\
\hline Female & $13(29.5)$ \\
\hline Intersex & $1(2.3)$ \\
\hline \multicolumn{2}{|l|}{ Race/Ethnicity } \\
\hline Non-Hispanic Asian & $1(2.3)$ \\
\hline Non-Hispanic Black or African American & $18(40.9)$ \\
\hline Non-Hispanic White & $18(40.9)$ \\
\hline Hispanic or Latino & $7(15.9)$ \\
\hline \multicolumn{2}{|l|}{ BMI } \\
\hline$<18.5$ & $2(4.5)$ \\
\hline $18.5-24.9$ & $9(20.5)$ \\
\hline $25-29.9$ & $10(22.7)$ \\
\hline $30-34.9$ & $9(20.5)$ \\
\hline $35.0-39.9$ & $6(13.6)$ \\
\hline$\geq 40$ & $8(18.1)$ \\
\hline \multicolumn{2}{|l|}{ Comorbidities } \\
\hline Autoimmune Disease & $5(11.4)$ \\
\hline Cancer & $7(15.9)$ \\
\hline Cardiovascular Disease & $14(31.8)$ \\
\hline Cerebrovascular Disease & $4(9.1)$ \\
\hline Chronic Immunosuppression & $6(13.6)$ \\
\hline Chronic Respiratory Disease & $15(34.1)$ \\
\hline Diabetes Mellitus & $14(31.8)$ \\
\hline History of Thromboembolic Event(s) & $3(6.8)$ \\
\hline Hypertension & $24(54.5)$ \\
\hline Hyperlipidemia & $14(31.8)$ \\
\hline Liver Disease & $4(9.1)$ \\
\hline Obesity (body mass index $\geq 30$ ) & $23(52.3)$ \\
\hline Renal Disease & $8(18.2)$ \\
\hline $1+$ & $42(95.5)$ \\
\hline $2+$ & $33(75.0)$ \\
\hline $3+$ & $29(65.9)$ \\
\hline
\end{tabular}

Disease Course Intervals Mean (Min, Max)

Symptom onset to hospital admission, days $\quad 9.4(-4,108)$

Symptom onset to death, days $\quad 35.2(1,230)$

Days hospitalized $26.4(0,188)$

Postmortem Interval (hours) $\quad 26.2(10,67)$

Pharmacologic Interventions $\quad n$ (\%)

Vasopressors

Antibiotics

Systemic Steroids

$38(86.4)$

41 (93.2)

$39(88.6)$

$34(77.3)$

$25(56.8)$

$10(22.7)$

$16(36.4)$

$4(9.1)$

$6(13.6)$

Nonpharmacologic Interventions

ECMO

10 (22.7)

18 (40.9)

36 (81.8)

Intubated

Tracheostomy

Chest Tube(s)

\section{Extended Data Table 1 Autopsy cohort demographics, comorbidities, and clinical}

848 intervention summary. (a) Summary of demographics and known comorbidities for autopsy

849 cases. (b) Summary of illness course and clinical care for autopsy cases. Data compiled from

850 available patient medical records. ECMO/extracorporeal membrane oxygenation. 


\begin{tabular}{|c|c|c|c|c|c|c|c|c|}
\hline $\begin{array}{l}\text { Patient } \\
\text { ID }\end{array}$ & Sex & $\begin{array}{l}\text { Age, } \\
\text { years }\end{array}$ & $\begin{array}{l}\text { Duration } \\
\text { of illness, } \\
\text { days }\end{array}$ & BMI & Comorbidities & Immediate Cause of death & $\begin{array}{l}\text { Highest level of } \\
\text { respiratory support }\end{array}$ & COVID-19 treatment(s) \\
\hline Patient 1 & M & 61 & 25 & 31.80 & DM, HTN, obesity & Bacterial sepsis and fungal pneumonia & intubation & Systemic steroids, systemic anticoagulation \\
\hline Patient 2 & $F$ & 71 & 14 & 39.60 & $\begin{array}{l}\text { HTN, HLD, COPD, breast cancer, cerebrovascular } \\
\text { event, Hx DVT/PE, CHF, AF, dementia, obesity, } \\
\text { hypothyroidism, anemia, seizure disorder }\end{array}$ & $\begin{array}{l}\text { Acute pyelonephritis with abscess and } \\
\text { likely sepsis }\end{array}$ & Intubation & Systemic steroids \\
\hline Patient 3 & M & 26 & 14 & 25.80 & Asthma & Lymphocytic myocarditis & Intubation, ECMO & Systemic anticoagulation \\
\hline Patient 4 & M & 68 & 18 & 31.40 & HTN, HLD, obesity & DAD & Intubation & $\begin{array}{l}\text { Systemic steroids, remdesivir, tocilizumab, } \\
\text { convalescent plasma }\end{array}$ \\
\hline Patient 5 & M & 41 & 42 & 50.60 & Obesity & Fungalpneumonia & intubation & Systemic steroids, Systemic anticoagulation \\
\hline Patient 6 & M & 62 & 19 & 45.00 & HTN, obesity & Acute bronchopnuemonia & Intubation & $\begin{array}{c}\text { Systemic steroids, systemic anticoagulation, } \\
\text { inhaled vasodilators }\end{array}$ \\
\hline Patient 7 & M & 60 & 7 & 24.30 & $\begin{array}{l}\text { DM, CML, HTN, AF, CHF, CAD s/p bypass, PVD, CKD, } \\
\text { Hx kidney transplant, chronic immunosuppression, } \\
\text { HLD, hyperparathyroidism, hypothyroidism, anemia }\end{array}$ & $\begin{array}{l}\text { Acute polymicrobial bronchopneumonia } \\
\text { superimposed on DAD }\end{array}$ & Intubation & Systemic anticoagulation \\
\hline Patient 8 & $\mathrm{~F}$ & 68 & 24 & $58.10^{\vdash}$ & $\begin{array}{l}\text { HTN, asthma, COPD, cerebrovascular disease, obesity, } \\
\text { anemia, chronic fatigue, fibromyalgia }\end{array}$ & $\begin{array}{l}\text { Acute polymicrobial bronchopneumonia } \\
\text { superimposed on DAD }\end{array}$ & Intubation & Systemic steroids, systemic anticoagulation \\
\hline Patient 9 & M & 43 & 66 & 34.00 & Obesity & Pneumonia and sepsis & $\begin{array}{l}\text { Intubation, } \\
\text { Tracheostomy, ECMO }\end{array}$ & $\begin{array}{l}\text { Systemic steroids, systemic anticoagulation, } \\
\text { paralytics, remdesivir, convalescent plasma }\end{array}$ \\
\hline Patient 10 & F & 70 & 29 & 35.43 & DM, HTN, HLD, CHF, COPD, obesity & Sepsis & Nasal Canula & Remdesivir \\
\hline Patient 11 & M & 50 & 58 & 36.70 & Obesity & Acute pneumonia & $\begin{array}{l}\text { Intubation, } \\
\text { Tracheostomy, ECMO }\end{array}$ & $\begin{array}{l}\text { Systemic steroids, systemic anticoagulation, } \\
\text { tocilizumab }\end{array}$ \\
\hline Patient 12 & M & 61 & 48 & 41.80 & DM, HTN, HLD, CHF, LV dysfunction, asthma, obesity & DAD, exudative phase & Intubation & Systemic anticoagulation \\
\hline Patient 13 & M & 48 & 82 & 41.00 & Obesity & DAD, organizing phase & $\begin{array}{l}\text { Intubation, } \\
\text { Tracheostomy, ECMO }\end{array}$ & $\begin{array}{l}\text { Systemic steroids, systemic anticoagulation, } \\
\text { tocilizumab, convalescent plasma }\end{array}$ \\
\hline Patient 14 & M & 64 & 16 & 30.60 & HTN, COPD, obesity & Acute bacterial bronchoneumonia & Intubation & Systemic steroids, systemic anticoagulation \\
\hline Patient 15 & M & 65 & 27 & 19.70 & HLD, sarcoidosis, chronic immunosuppression & Fungal pneumonia and sepsis & Intubation & $\begin{array}{l}\text { Systemic steroids, systemic anticoagulation, } \\
\text { remdesivir, convalescent plasma }\end{array}$ \\
\hline Patient 16 & M & 87 & 8 & 26.90 & DM, HTN, HLD, CAD, CHF, ESRD & DAD, exudative phase & AVAPS & $\begin{array}{c}\text { Systemic steroids, systemic anticoagulation, } \\
\text { convalescent plasma }\end{array}$ \\
\hline Patient 17 & M & 36 & 14 & 27.17 & Drug abuse & Bilateral bronchopneumonia & Intubation, ECMO & Systemic steroids, systemic anticoagulation \\
\hline Patient 18 & $\mathrm{~F}$ & 79 & 9 & 32.60 & $\begin{array}{l}\text { DM, HTN, COPD, Hx DVT, CAD, cirrhosis, CKD, } \\
\text { obesity, anemia, seizure disorder }\end{array}$ & DAD, exudative phase & Intubation & Systemic steroids \\
\hline Patient 19 & M & 43 & 7 & 21.90 & DM & Sudden cardiac death & Intubation & Systemic steroids, systemic anticoagulation \\
\hline Patient 20 & M & 42 & 99 & 23.50 & DM, HLD & DAD, proliferative and fibrosing phase & $\begin{array}{l}\text { Intubation, } \\
\text { Tracheostomy, ECMO }\end{array}$ & $\begin{array}{l}\text { Systemic steroids, systemic anticoagulation, } \\
\text { convalescent plasma }\end{array}$ \\
\hline Patient 21 & M & 77 & 12 & 25.20 & $\begin{array}{c}\text { DM, HTN, COPD, pulmonary fibrosis, CAD, CHF, CKD, } \\
\text { Hx prostate cancer, cerebrovascular disease }\end{array}$ & DAD, exudative phase & $\begin{array}{l}\text { High flow nasal canula, } \\
\text { BiPAP }\end{array}$ & Systemic steroids, systemic anticoagulation \\
\hline Patient 22 & M & 64 & 4 & 29.90 & HTN, HLD & DAD/ARDS & Intubation & Systemic steroids, systemic anticoagulation \\
\hline Patient 23 & M & 79 & 23 & 28.00 & & Pulmonary hemorrhage & Intubation & Systemic steroids, systemic anticoagulation \\
\hline Patient 24 & M & 59 & 12 & 34.20 & $\begin{array}{l}\text { Hx recurrent aspiration pneumonia, MS, chronic } \\
\text { immunosuppression, obesity }\end{array}$ & Acute pneumonia & BiPAP & Systemic steroids, systemic anticoagulation \\
\hline Patient 25 & $F$ & 91 & 9 & $16.50^{\mathrm{C}}$ & $\begin{array}{l}\text { Cardiomyopathy, arrhythmia, dementia, inflammatory } \\
\text { polyneuropathy, anemia }\end{array}$ & DAD, acute phase. & None & Systemic steroids, remdesivir \\
\hline Patient 26 & M & 48 & 29 & 28.20 & & Cerebral hemorrhage & Intubation, ECMO & $\begin{array}{l}\text { Systemic steroids, systemic anticoagulation, } \\
\text { remdesivir }\end{array}$ \\
\hline Patient 27 & $\begin{array}{l}\text { Inter- } \\
\text { sex }\end{array}$ & 76 & 1 & $20.90^{\top}$ & $\begin{array}{l}\text { Turner Syndrome, aortic stenosis, sick sinus syndrome } \\
\text { s/p pacemaker, dementia, hypothyroidism }\end{array}$ & $\begin{array}{l}\text { Bronchopneumonia and DAD, exudative } \\
\text { phase }\end{array}$ & Intubation & $\begin{array}{l}\text { Systemic steroids, systemic anticoagulation, } \\
\text { remdesivir }\end{array}$ \\
\hline Patient 28 & $\mathrm{~F}$ & 44 & 7 & 30.9 & HTN, obesity & $\begin{array}{l}\text { Pulmonary thromboembolic disease in } \\
\text { the setting of DAD, exudative phase of }\end{array}$ & None & \\
\hline Patient 29 & M & 60 & 204 & 24.91 & $\begin{array}{l}\text { HTN, ILD, cerebrovascular disease, CAD, RA, Hx lung } \\
\text { transplant, chronic immunosuppression }\end{array}$ & $\begin{array}{l}\text { Herpetic tracheobronchitis and DAD, s/p } \\
\text { bilateral lung transplantation }\end{array}$ & $\begin{array}{l}\text { Intubation, } \\
\text { Tracheostomy, ECMO }\end{array}$ & Systemic steroids, systemic anticoagulation \\
\hline Patient 30 & $F$ & 70 & 15 & 26.00 & $\begin{array}{l}\mathrm{HTN} \text {, ILD, PH, CHF, CAD, PAD, CKD, ESRD, congenital } \\
\text { heart malformation, calciphylaxis }\end{array}$ & $\begin{array}{l}\text { Bacterial pneumonia, SARS-CoV-2 } \\
\text { infection }\end{array}$ & Intubation & $\begin{array}{c}\text { Systemic steroids, systemic anticoagulation, } \\
\text { remdesivir }\end{array}$ \\
\hline Patient 31 & M & 59 & 18 & 26.50 & DM, HTN, HLD & Bacterial pneumonia & $\begin{array}{l}\text { Intubation, } \\
\text { Tracheostomy }\end{array}$ & $\begin{array}{l}\text { Systemic steroids, systemic anticoagulation, } \\
\text { remdesivir }\end{array}$ \\
\hline Patient 32 & $\mathrm{~F}$ & 71 & 6 & 31.50 & $\begin{array}{c}\text { Asthma, COPD, sarcoidosis, cirrhosis, ESRD, } \mathrm{Hx} \\
\text { endocarditis, obesity, hypothyroidism, seizure } \\
\text { disorder, anemia }\end{array}$ & Right heart failure & BIPAP & Systemic steroids \\
\hline Patient 33 & M & 71 & 76 & 29.1 & HTN, CKD, Hx Lyme disease & Bacterial pneumonia & High fiow nasal canula & Systemic steroids, systemic anticoagulation \\
\hline Patient 34 & M & 87 & 36 & 22.20 & $\begin{array}{l}\text { HLD, MM, COPD, CKD, seizure disorder, chronic } \\
\text { immunosuppression, hypothyroidism }\end{array}$ & DAD, organizing to fibrosing phase & Intubation & Systemic steroids, remdesivir \\
\hline Patient 35 & F & 45 & 25 & 63.00 & $\begin{array}{l}\text { DM, HTN, HLD, COPD, obesity, chronic lower } \\
\text { extremetity lymphedema }\end{array}$ & DAD, organixing phase & Intubation & $\begin{array}{l}\text { Systemic steroids, systemic anticoagulation, } \\
\text { remdesivir }\end{array}$ \\
\hline Patient 36 & $F$ & 6 & 4 & 17.40 & $\begin{array}{c}\text { Dravet syndrome, SCN1A gene mutation, seizure } \\
\text { disorder }\end{array}$ & $\begin{array}{l}\text { Acute cerebral ischemia with tonsillar } \\
\text { herniation }\end{array}$ & Intubation & Systemic steroids, remdesivir \\
\hline Patient 37 & M & 63 & 5 & 19.80 & $\begin{array}{l}\text { DM, HTN, Hx femoral artery thrombosis, CHF, CAD, } \\
\text { PAD, AF, cardiomyopathy, Hx cardiac tamponade, } \\
\text { hepatitis C, abnormal liver function, drug abuse }\end{array}$ & Bronchopneumonia & Intubation & Systemic steroids, systemic anticoagulation \\
\hline Patient 38 & M & 71 & 13 & 40.20 & HTN, HLD, COPD, prostate cancer, obesity & Bronchopneumonia & Intubation & $\begin{array}{l}\text { Systemic steroids, systemic anticoagulation, } \\
\text { remdesivir }\end{array}$ \\
\hline Patient 39 & M & 27 & 31 & 39.20 & Obesity & $\begin{array}{l}\text { DAD, organizing to fibrotic phase and } \\
\text { multiple pulmonary infarcts }\end{array}$ & $\begin{array}{l}\text { Intubation, } \\
\text { Tracheostomy, ECMO }\end{array}$ & $\begin{array}{l}\text { Systemic steroids, systemic anticoagulation, } \\
\text { remdesivir }\end{array}$ \\
\hline Patient 40 & $F$ & 68 & 47 & 35.11 & HTN, uterine cancer, obesity & $\begin{array}{l}\text { Sepsis with signs of cardiac dysfunction } \\
\text { in the setting of DAD, proliferative and } \\
\text { fibrotic phase }\end{array}$ & $\begin{array}{l}\text { Intubation, } \\
\text { Tracheostomy }\end{array}$ & $\begin{array}{c}\text { Systemic steroids, systemic anticoagulation, } \\
\text { remdesivir }\end{array}$ \\
\hline Patient 41 & $F$ & 75 & 33 & 24.94 & DM, HTN, HLD, hypothyroidism & DAD, proliferative and fibrotic phase & Intubation & Systemic steroids \\
\hline Patient 42 & M & 68 & 230 & 36.87 & $\begin{array}{l}C A D \text {, hepatitis } \mathrm{A} \text {, liver failure, } \mathrm{Hx} \text { liver transplant, } \\
\text { chronic immunosuppression, obesity }\end{array}$ & $\begin{array}{l}\text { Massive hepatic necrosis, status-post } \\
\text { liver transplant }\end{array}$ & $\begin{array}{l}\text { Intubation, } \\
\text { Trachesostomy }\end{array}$ & Systemic steroids, systemic anticoagulation \\
\hline Patient 43 & F & 61 & 18 & 32.22 & DM, HTN, breast cancer, CAD, obesity & $D A D$, exudative and proliferative phase & Intubation & Systemic steroids, systemic anticoagulation \\
\hline $\begin{array}{l}\text { Patient } 44 \\
54\end{array}$ & M & 21 & 65 & 58.00 & Obesity & $\begin{array}{l}\text { Bacterial pneumonia superimposed on } \\
\text { DAD, fibrosing stage }\end{array}$ & Intubation, ECMO & $\begin{array}{c}\text { Systemic steroids, systemic anticoagulation, } \\
\text { remdesivir, tocilizumab }\end{array}$ \\
\hline
\end{tabular}


855 Extended Data Table 2 Individual case demographics and clinical summary. Data obtained

856 from available medical records. AF/atrial fibrillation, AVAPS/average volume-assured pressure

857 support, $\mathrm{BiPAP} /$ bilevel positive airway pressure, $\mathrm{CAD} /$ coronary artery disease, $\mathrm{CHF} /$ congestive

858 heart failure, $\mathrm{CKD} /$ chronic kidney disease, $\mathrm{CML} /$ chronic myeloid leukemia, $\mathrm{COPD} /$ chronic

859 obstructive pulmonary disease, DAD/diffuse alveolar damage, DM/diabetes mellitus, DVT/deep

860 vein thrombosis, ECMO/extracorporeal membrane oxygenation, ESRD/end-stage renal disease,

861 HLD/hyperlipidemia, HTN/hypertension, Hx/historical, ILD/interstitial lung disease, LV/left

862 ventricular, MS/multiple sclerosis, $\mathrm{PE} /$ pulmonary embolism, PVD/peripheral vascular disease,

$863 \mathrm{PH} /$ pulmonary hypertension, s/p/status post.

864 
a

\begin{tabular}{|c|c|c|}
\hline Tissue Category & DOI (days) & $\begin{array}{l}\text { Avg. N gene copies/ng } \\
\text { RNA (SD) }\end{array}$ \\
\hline \multirow{3}{*}{ Respiratory Tract } & 514 & $9,210.10(43,179.20)$ \\
\hline & $15-30$ & $19.67(77.98)$ \\
\hline & 231 & $0.65(2.61)$ \\
\hline \multirow{3}{*}{ Cardiovascular } & $\$ 14$ & $38.75(106.08)$ \\
\hline & $15-30$ & $0.59(3.43)$ \\
\hline & 231 & $0.42(2.51)$ \\
\hline \multirow{3}{*}{ Lymphoid } & $\leq 14$ & $30.01(157.86)$ \\
\hline & $15-30$ & $0.35(1.28)$ \\
\hline & 231 & $0.73(3.83)$ \\
\hline \multirow{3}{*}{ Gastrointestinal } & $\leq 14$ & $24.68(99.37)$ \\
\hline & $15-30$ & $0.87(4.38)$ \\
\hline & 231 & $0.24(2.17)$ \\
\hline \multirow{3}{*}{ Renal \& Endocrine } & $\leqslant 14$ & $12.76(59.01)$ \\
\hline & $15-30$ & $0.03(0.16)$ \\
\hline & 231 & $0.04(0.33)$ \\
\hline \multirow{3}{*}{ Reproductive } & $\leq 14$ & $0.36(0.58)$ \\
\hline & $15-30$ & $1.87(6.72)$ \\
\hline & 231 & $0.01(0.02)$ \\
\hline \multirow{3}{*}{$\begin{array}{l}\text { Muscle, Nerve, Adipose, } \\
\text { \& Skin }\end{array}$} & $s 14$ & $27.50(101.13)$ \\
\hline & $15-30$ & $50.65(284.46)$ \\
\hline & 231 & $0.54(3.03)$ \\
\hline \multirow{3}{*}{ Ocular } & $\leq 14$ & $57.40(242.40)$ \\
\hline & $15-30$ & $0.07(0.24)$ \\
\hline & 231 & $0.03(0.12)$ \\
\hline \multirow{3}{*}{ Central Nervous System } & $s 14$ & $32.93(121.69)$ \\
\hline & $15-30$ & $2.37(7.34)$ \\
\hline & 231 & $0.39(1.40)$ \\
\hline
\end{tabular}

b

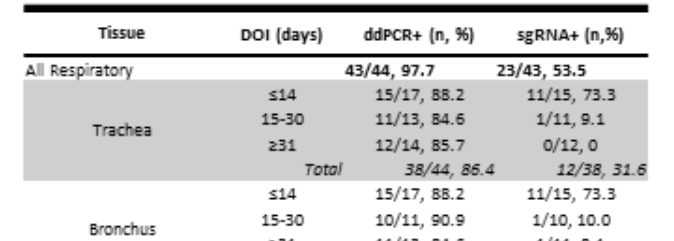

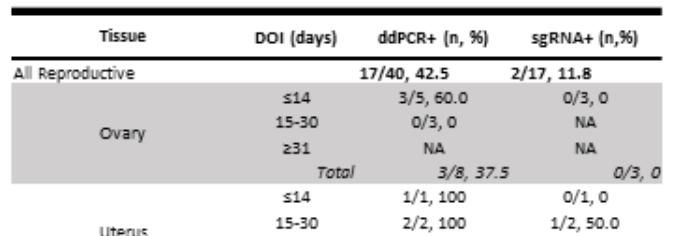
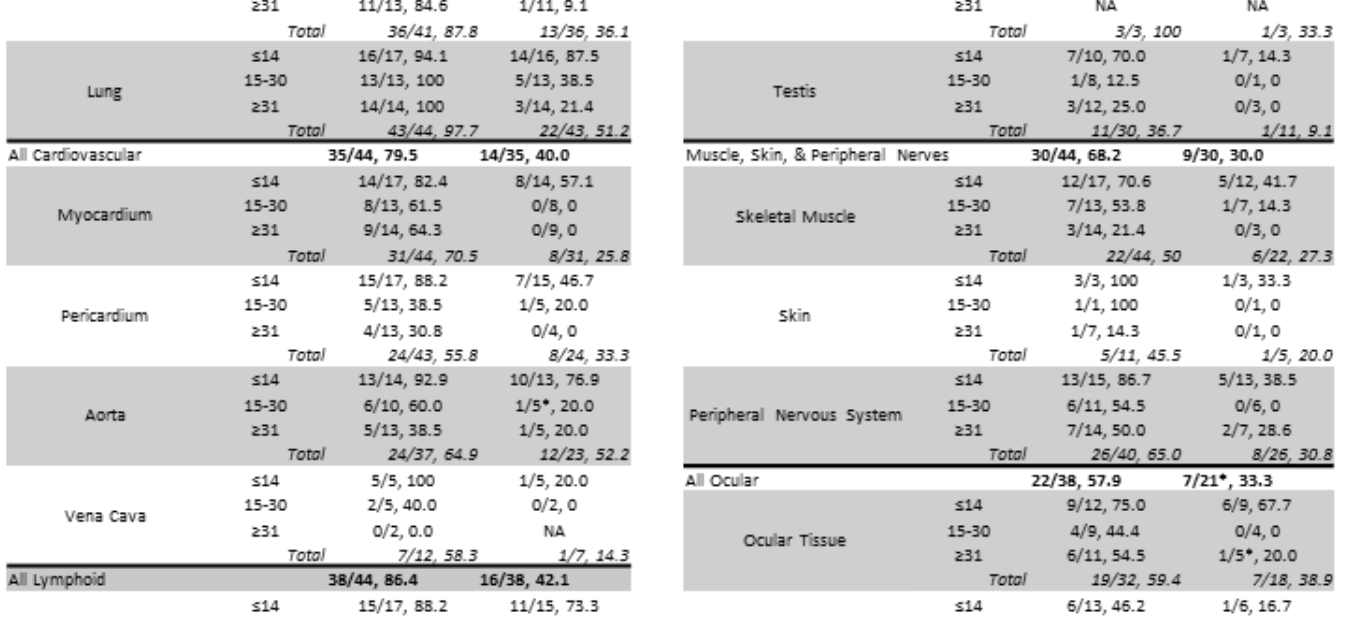

$\begin{array}{lrrr} & & & \\ & \$ 14 & 15 / 17,88.2 & 11 / 15,73.3 \\ \text { LN from Thorax } & 15-30 & 11 / 13,84.6 & 2 / 11,18.2\end{array}$

\begin{tabular}{cccc}
231 & $12 / 13,92.3$ & \multicolumn{1}{c}{$2 / 12,16.7$} \\
& Total & $38 / 43,88.4$ & $15 / 38,39.5$
\end{tabular}

\begin{tabular}{|c|c|c|c|}
\hline & & $38 / 43,88.4$ & $15 / 38,39.5$ \\
\hline \multirow{4}{*}{ LN from Abdomen } & s14 & $6 / 11,54.5$ & $2 / 6,33.3$ \\
\hline & $15-30$ & $4 / 8,50$ & $0 / 4,0$ \\
\hline & 231 & $1 / 5,20$ & $0 / 1,0$ \\
\hline & Total & $11 / 24,45.8$ & $2 / 11,18.2$ \\
\hline & $s 14$ & $12 / 17,70.6$ & $3 / 12,25.0$ \\
\hline
\end{tabular}

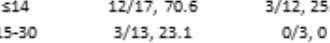

$231 \quad 2 / 14,14.3 \quad 0 / 2,0$

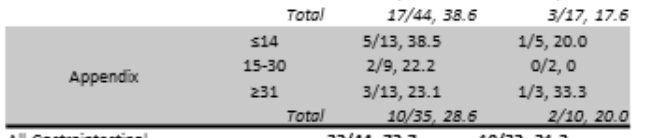

\begin{tabular}{lccc} 
& Totol & $10 / 35,28.6$ & $2 / 10,2$ \\
\hline All Gastrointestinal & $32 / 44,72.7$ & $10 / 32,31.3$
\end{tabular}

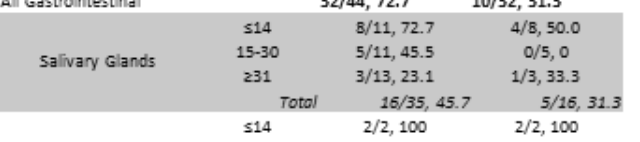

$\begin{array}{cccc} & 15-30 & 3 / 5,60.0 & 2 / 3,66.7 \\ \text { Tongue } & 231 & 3 / 5,60.0 & 0 / 3,0\end{array}$

$\begin{array}{lll}\text { Total } & 8 / 12,66.7 & 4 / 8,50.0\end{array}$

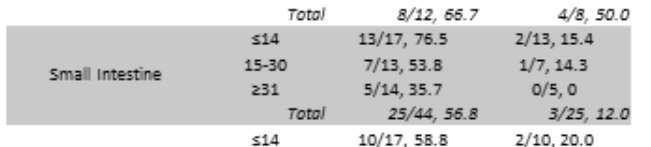

$514 \quad 10 / 17,56.8 \quad 2 / 10,20.0$

15-30 $\quad 4 / 11,36.4 \quad 0 / 4,0$

$231 \quad 2 / 14,14.3 \quad 0 / 2,0$

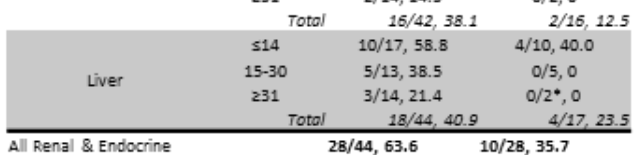
$4 / 17,23.5$

\begin{tabular}{|c|c|c|c|}
\hline All Renal \& Endocrine & & $/ 44,63.6$ & $10 / 28,35.7$ \\
\hline \multirow{4}{*}{ Kidney } & s14 & $12 / 17,70.6$ & $4 / 12,33.3$ \\
\hline & $15-30$ & $5 / 13,38.5$ & $0 / 5,0$ \\
\hline & 231 & $3 / 14,21.4$ & $1 / 3,33.3$ \\
\hline & Total & $20 / 44,45.5$ & $5 / 20,25.0$ \\
\hline \multirow{4}{*}{ Adrenal Gland } & $s 14$ & $12 / 16,75.0$ & $5 / 12,41.7$ \\
\hline & $15-30$ & $4 / 13,30.8$ & $0 / 4,0$ \\
\hline & 231 & $5 / 14,35.7$ & $0 / 5,0$ \\
\hline & Total & $21 / 43,48.8$ & $5 / 21,23.8$ \\
\hline \multirow{4}{*}{ Thyroid } & $\$ 14$ & $10 / 16,62.5$ & $7 / 10,70.0$ \\
\hline & $15-30$ & $4 / 12,33.3$ & $0 / 4,0$ \\
\hline & 231 & $3 / 13,23.1$ & $0 / 3,0$ \\
\hline & Total & $17 / 41,41.5$ & $7 / 17,41.2$ \\
\hline \multirow{4}{*}{ Pancreas } & $s 14$ & $11 / 17,64.7$ & $3 / 11,27.3$ \\
\hline & $15-30$ & $3 / 12,25.0$ & $0 / 3,0$ \\
\hline & 231 & $2 / 14,14.3$ & $0 / 2,0$ \\
\hline & Total & $16 / 43,37.2$ & $3 / 16,18$ \\
\hline
\end{tabular}

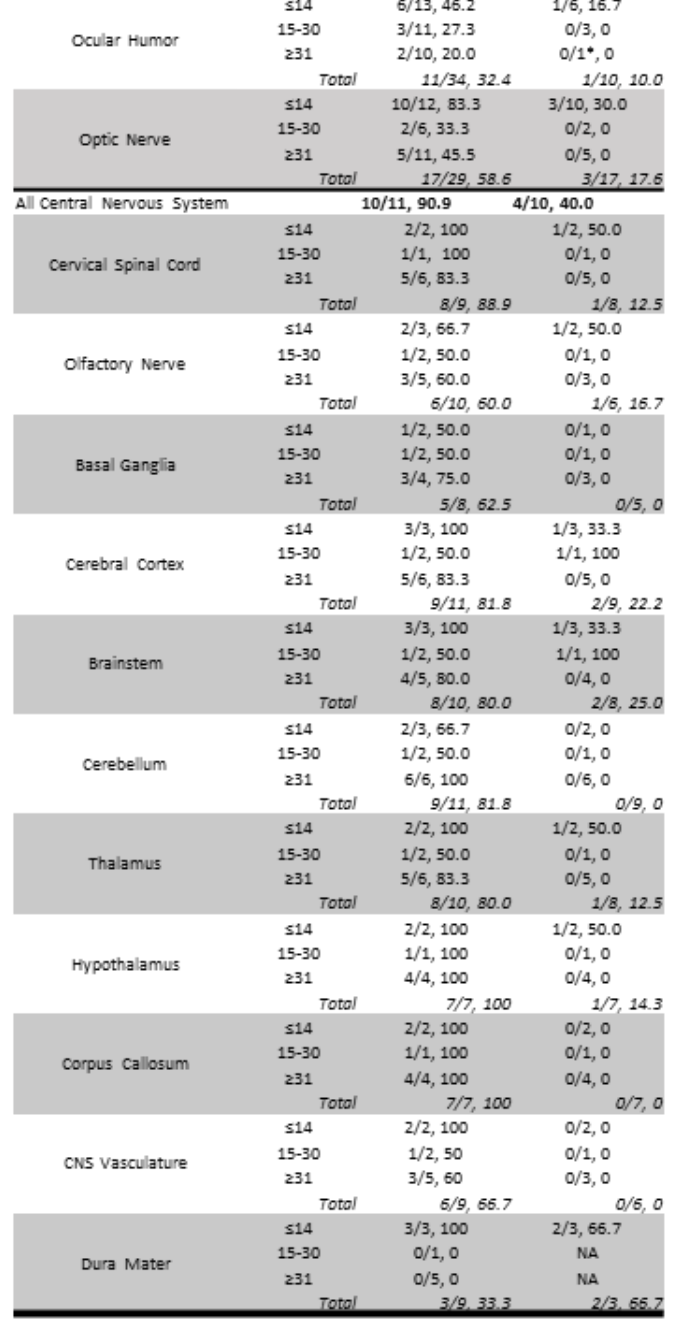


866 Extended Data Table 3 Summary of SARS-CoV-2 RNA and sgRNA by tissue category over

867 time. (a) Summary of the average nucleocapsid gene copies/ng RNA across cases by tissue

868 category and duration of illness (days). (b) Summary of the number and percentage of cases with

869 SARS-CoV-2 RNA detected via droplet digital (dd)PCR by tissue category for all cases and by

870 tissue and duration of illness (days). The number and percentage of tissues positive for ddPCR

871 that were additionally positive for subgenomic (sg)RNA PCR is listed in the right most column.

$872 *$ A tissue positive via ddPCR was not tested via sgRNA PCR. CNS/central nervous system,

873 LN/lymph node.

874 


\begin{tabular}{|c|c|}
\hline Cell Type & Locations \\
\hline Bile duct epithelium & Liver \\
\hline Chondrocytes & Bronchial cartilage rings \\
\hline Collecting duct epithelium & Kidney \\
\hline Distal tubule epithelium & Kidney \\
\hline Endocrine cells of adrenal & Adrenal gland \\
\hline Endocrine cells of thyroid & Thyroid \\
\hline Endothelium & Vasculature, all \\
\hline Ependyma & Brain \\
\hline Exocrine cells of pancreas & Pancreas \\
\hline Fibroblast-like cells & Pericardium, heart, trachea, bronchus \\
\hline Germ cells & Testis \\
\hline Glandular epithelum & Uterus \\
\hline Glia & Brain, all locations \\
\hline Hepatocytes & Liver \\
\hline Hyaline Membrane & Lung \\
\hline Interstitial cells of endometrium & Uterus \\
\hline Intimal cells & Aorta \\
\hline Kupffer cells & Liver \\
\hline Leydig cells & Testis \\
\hline Mononuclear leukocytes & Lung, spleen, lymph nodes, lymphoid aggregates of GI \\
\hline Mucosal epithelium & Small intestine, colon \\
\hline Mucus secreting epithelium, salivary type & Salivary glands, trachea, bronchus \\
\hline Myocytes, Cardiac & Heart \\
\hline Myocytes, Striated & Psoas muscle \\
\hline Myocytes, Smooth & Uterus, GI \\
\hline Neurons & Brain, all locations \\
\hline Parietal cells & Kidney, Bowman's capsule \\
\hline Pneumocytes, type I \& II & Lung \\
\hline Purkinje cell & Cerebellum \\
\hline Schwann cells & Nerves, all \\
\hline Sertoli cells & Testis \\
\hline Stratified epithelium (\& basal layer) & Trachea, esophagus \\
\hline Stromal cells & Pericardium, uterus, ovary \\
\hline Vascular smooth muscle & Arteries, all \\
\hline
\end{tabular}

876 Extended Data Table 4 SARS-CoV-2 cellular tropism. Summary of cell types that were

877 identified as SARS-CoV-2 positive by ISH, and the corresponding anatomic sites in which this

878 was observed. 


\begin{tabular}{|c|c|}
\hline Cause of Death & $\mathrm{N}=44$ \\
\hline Death with (but not from) COVID-19 & $5(11 \%)$ \\
\hline Death from COVID-19 or complications & $39(89 \%)$ \\
\hline Pulmonary Findings ${ }^{1}$ & $\begin{array}{c}\mathrm{N}(\%) \text { or } \\
\text { Median (IQR) }\end{array}$ \\
\hline Left Lung Weight $(\mathrm{g})^{2}$ & $795(327)$ \\
\hline Right Lung Weight $(\mathrm{g})^{2}$ & $820(365)$ \\
\hline Combined Lung Weight (g) & $1600(528)$ \\
\hline \multicolumn{2}{|l|}{ Diffuse Alveolar Damage } \\
\hline Exudative & $14(32 \%)$ \\
\hline Proliferate & $15(34 \%)$ \\
\hline Fibrosing & $7(16 \%)$ \\
\hline Not Found & $8(18 \%)$ \\
\hline Acute Pneumonia & $27(61 \%)$ \\
\hline Pulmonary Edema & $30(68 \%)$ \\
\hline Pulmonary Hemorrhage (at least focal) & $14(32 \%)$ \\
\hline Pulmonary Thromboembolism, Infarction & $10(23 \%)$ \\
\hline $\begin{array}{l}\text { Emphysematous changes (underlying } \\
\text { COPD) }\end{array}$ & $12(27 \%)$ \\
\hline \multicolumn{2}{|l|}{ Cardiac Findings } \\
\hline Heart Weight (g) & $500(175)$ \\
\hline Myocardial Infiltrate & $4(9 \%)$ \\
\hline $\begin{array}{l}\text { Focal infiltrate without myocyte } \\
\text { necrosis }\end{array}$ & $3(7 \%)$ \\
\hline $\begin{array}{l}\text { Diffuse lymphocytic myocarditis } \\
\text { Myocardial Ischemic Necrosis }\end{array}$ & $1(2 \%)$ \\
\hline Remote, fibrotic & $5(11 \%)$ \\
\hline Acute microscopic ischemia & $4(9 \%)$ \\
\hline $\begin{array}{l}\text { Coronary Artery Disease with } \geq 50 \% \text { in at } \\
\text { least } 1 \text { artery }\end{array}$ & $16(36 \%)$ \\
\hline \multicolumn{2}{|l|}{ Renal Findings } \\
\hline Left Kidney Weight $(\mathrm{g})^{4}$ & $180(107)$ \\
\hline Right Kidney Weight $(\mathrm{g})^{4}$ & $168(79)$ \\
\hline $\begin{array}{l}\text { Changes consistent with Acute Kidney } \\
\text { Injury }\end{array}$ & $17(39 \%)$ \\
\hline $\begin{array}{l}\text { Changes consistent with Diabetic } \\
\text { glomerulopathy }\end{array}$ & $10(23 \%)$ \\
\hline \multicolumn{2}{|l|}{ Splenic Findings } \\
\hline Splenic Weight (g) & $235(215)$ \\
\hline Follicular hyperplasia & $15(34 \%)$ \\
\hline \multicolumn{2}{|l|}{ Lymphodepletion } \\
\hline Present & $8(18 \%)$ \\
\hline Some, Partial Preservation & $34(77 \%)$ \\
\hline No Lymphodepletion & $2(5 \%)$ \\
\hline Red Pulp Congestion & $35(80 \%)$ \\
\hline Infarction & $2(5 \%)$ \\
\hline
\end{tabular}

\begin{tabular}{|c|c|}
\hline Lymph Node Findings ${ }^{5}$ & $\begin{array}{c}\mathrm{N}(\%) \text { or } \\
\text { Median (IQR) }\end{array}$ \\
\hline \multicolumn{2}{|l|}{ Lymphodepletion } \\
\hline Present & $5(12 \%)$ \\
\hline Some, Partial Preservation & $4(10 \%)$ \\
\hline No Lymphodepletion & $31(78 \%)$ \\
\hline \multicolumn{2}{|l|}{ Follicular Hyperplasia } \\
\hline Present & $22(55 \%)$ \\
\hline Present, regressed & $2(5 \%)$ \\
\hline Paracortical Hyperplasia & $32(80 \%)$ \\
\hline Plasmacytosis & $19(48 \%)$ \\
\hline Plasmablasts noted & $4(10 \%)$ \\
\hline \multicolumn{2}{|l|}{ Hepatic Findings $^{3}$} \\
\hline Liver Weight $(\mathrm{g})^{4}$ & $1670(900)$ \\
\hline \multicolumn{2}{|l|}{ Hepatic necrosis } \\
\hline None & $30(70 \%)$ \\
\hline Zonal & $12(28 \%)$ \\
\hline \% Zonal Necrosis & $30 \%(40 \%)$ \\
\hline Massive & $1(2 \%)$ \\
\hline \multicolumn{2}{|l|}{ Steatosis } \\
\hline None to Minimal & $24(56 \%)$ \\
\hline Mild & $14(33 \%)$ \\
\hline Moderate & $5(12 \%)$ \\
\hline Steatohepatitis & $5(12 \%)$ \\
\hline \multicolumn{2}{|l|}{ Portal Inflammation } \\
\hline None to Minimal & $16(37 \%)$ \\
\hline Mild & $23(53 \%)$ \\
\hline Moderate & $4(9 \%)$ \\
\hline \multicolumn{2}{|l|}{ Fibrosis } \\
\hline None & $27(63 \%)$ \\
\hline Periportal or perisinusoidal & $6(14 \%)$ \\
\hline Periportal and perisinusoidal & $1(2 \%)$ \\
\hline Bridging fibrosis & $6(14 \%)$ \\
\hline Cirrhosis & $3(7 \%)$ \\
\hline \multicolumn{2}{|l|}{ Central Nervous System Findings $(\mathrm{N}=11)$} \\
\hline Brain Weight (g) & $1350(230)$ \\
\hline $\begin{array}{l}\text { Hypoxic/Ischemic Injury (focal or } \\
\text { diffuse) }\end{array}$ & $5(45 \%)$ \\
\hline Vascular congestion & $5(45 \%)$ \\
\hline Focal (microscopic) hemorrhage & $2(18 \%)$ \\
\hline No pathological findings & $3(27 \%)$ \\
\hline
\end{tabular}

880 Extended Data Table 5 Histopathologic findings of COVID-19 autopsy cases. Summary of

881 histopathologic findings across organ system across 44 autopsy cases. Central nervous system

882 findings are reported for the 11 cases in which consent for sampling was obtained. ${ }^{1}$ Includes one 
883 case in which the COVID lungs were transplanted and data from explanted lungs used in table.

$884{ }^{2}$ Individual lung weights were missing in 4 cases. ${ }^{3}$ Findings missing on 1 case due to extreme 885 autolysis. ${ }^{4}$ Weight missing on one case. ${ }^{5}$ Lymph node findings missing in 4 cases 


\section{Supplementary Files}

This is a list of supplementary files associated with this preprint. Click to download.

- SupplementaryData1.xlsx

- SupplementaryData2.xlsx 